\title{
Cited2 Regulates Neocortical Layer II/III Generation and Somatosensory Callosal Projection Neuron Development and Connectivity
}

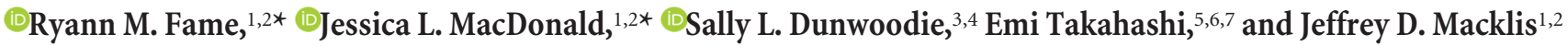 \\ ${ }^{1}$ Department of Stem Cell and Regenerative Biology, Center for Brain Science, and ${ }^{2}$ Harvard Stem Cell Institute, Harvard University, Cambridge, \\ Massachusetts 02138, ${ }^{3}$ Developmental and Stem Cell Biology Division, Victor Chang Cardiac Research Institute, Darlinghurst, Sydney, New South Wales, \\ 2052 Australia, ${ }^{4}$ Faculties of Medicine and Science, University of New South Wales, Kensington, Sydney, New South Wales, 2052 Australia, ${ }^{5}$ Division of \\ Newborn Medicine, Department of Medicine, Boston Children's Hospital, Harvard Medical School, Boston, Massachusetts 02115, ${ }^{6} \mathrm{Fetal}-$ Neonatal \\ Neuroimaging and Developmental Science Center, Boston, Massachusetts 02115, and ${ }^{7}$ Athinoula A. Martinos Center for Biomedical Imaging, Charlestown, \\ Massachusetts 02129
}

The neocortex contains hundreds to thousands of distinct subtypes of precisely connected neurons, allowing it to perform remarkably complex tasks of high-level cognition. Callosal projection neurons (CPN) connect the cerebral hemispheres via the corpus callosum, integrating cortical information and playing key roles in associative cognition. CPN are a strikingly diverse set of neuronal subpopulations, and development of this diversity requires precise control by a complex, interactive set of molecular effectors. We have found that the transcriptional coregulator Cited2 regulates and refines two stages of CPN development. Cited2 is expressed broadly by progenitors in the embryonic day 15.5 subventricular zone, during the peak of superficial layer CPN birth, with a progressive postmitotic refinement in expression, becoming restricted to CPN of the somatosensory cortex postnatally. We generated progenitor-stage and postmitotic forebrain-specific Cited 2 conditional knock-out mice, using the Emx1-Cre and NEX-Cre mouse lines, respectively. We demonstrate that Cited2 functions in progenitors, but is not necessary postmitotically, to regulate both (1) broad generation of layer II/III CPN and (2) acquisition of precise area-specific molecular identity and axonal/dendritic connectivity of somatosensory CPN. This novel CPN subtypespecific and area-specific control from progenitor action of Cited 2 adds yet another layer of complexity to the multistage developmental regulation of neocortical development.

Key words: arealization; callosum; neocortex; neuronal differentiation; somatosensory

Significance Statement

This study identifies Cited 2 as a novel subtype-specific and area-specific control over development of distinct subpopulations within the broad population of callosal projection neurons (CPN), whose axons connect the two cerebral hemispheres via the corpus callosum (CC). Currently, how the remarkable diversity of CPN subtypes is specified, and how they differentiate to form highly precise and specific circuits, are largely unknown. We found that Cited 2 functions within subventricular zone progenitors to both broadly regulate generation of superficial layer CPN throughout the neocortex, and to refine precise area-specific development and connectivity of somatosensory CPN. Gaining insight into molecular development and heterogeneity of CPN will advance understanding of both diverse functions of $\mathrm{CPN}$ and of the remarkable range of neurodevelopmental deficits correlated with CPN/CC development.

\section{Introduction}

The neocortex contains hundreds to thousands of distinct neuronal subtypes that enable it to perform remarkably complex

Received Nov. 11, 2015; revised April 26, 2016; accepted May 4, 2016.

Author contributions: R.M.F., J.L.M., and J.D.M. designed research; R.M.F., J.L.M., and E.T. performed research;

S.L.D. contributed unpublished reagents/analytic tools; R.M.F., J.L.M., E.T., and J.D.M. analyzed data; R.M.F., J.L.M., and J.D.M. wrote the paper. tasks. Callosal projection neurons $(\mathrm{CPN})$ are the broad population of commissural neurons whose axons connect the two cerebral hemispheres via the corpus callosum (CC), the largest axonal 
tract in the mammalian brain. CPN are excitatory pyramidal projection neurons whose cell bodies reside in neocortical layers II/III ( $\sim 80 \%$ in mouse), V ( $\sim 20 \%)$, and VI (a few percent; Catapano et al., 2001; Fame et al., 2011; Greig et al., 2013), and play $\mathrm{key}$, diverse roles in complex associative and integrative cognition. CPN in the four primary functional neocortical areas are molecularly, morphologically, and functionally diverse (Lomber et al., 1994; Olivares et al., 2001; Grove and Fukuchi-Shimogori, 2003; Benavides-Piccione et al., 2006; O'Leary et al., 2007). Further, subpopulations of CPN maintain other noncallosal projections to the contralateral or ipsilateral striatum, the primary somatosensory cortex, or frontal areas (Wilson, 1987; Mitchell and Macklis, 2005; Fame et al., 2011). CPN are thus a strikingly heterogeneous set of neuronal subpopulations, requiring a complex and interactive set of molecular controls to precisely regulate development of their distinct subpopulations.

Currently, how the remarkable diversity of CPN subtypes and connectivity is specified, and how they differentiate to form highly precise and specific circuits, are largely unknown. We previously identified a combinatorially expressed set of genes that both define CPN as a broad population and identify novel subpopulations of CPN during development (Molyneaux et al., 2009). Cited 2 encodes a transcriptional coregulator that is significantly enriched in CPN over other cortical projection neuron subpopulations, with particularly high expression at early stages of CPN development (Molyneaux et al., 2009). CITED2 functions as a transcriptional coactivator by interacting with CBP/ p300 (Bhattacharya et al., 1999; Freedman et al., 2003), or as a transcriptional corepressor by competing with transcription factors for binding to CBP/p300 (Freedman et al., 2003; Lou et al., 2011). Cited2 is critical for proper development of multiple systems, including the heart, lung, lens, placenta, and blood, in addition to neural tube closure (Bamforth et al., 2001, 2004; Barbera et al., 2002; Weninger et al., 2005; Withington et al., 2006; Chen et al., 2008, 2009; Xu et al., 2008; Kranc et al., 2009). Although Cited 2 function has not been investigated in cortical development, in these other systems CITED2 interacts with or regulates transcription factors known to function critically in cortical specification and development, including LHX2 (Glenn and Maurer, 1999), PAX6 (Chen et al., 2008, 2009), and AP2 $\gamma$ (Bamforth et al., 2001).

Here, we demonstrate that Cited 2 regulates and refines two stages of CPN development. Cited 2 is expressed broadly by progenitors of the embryonic day (E) 15.5 subventricular zone (SVZ) during the peak of superficial layer CPN birth, with a progressive postmitotic refinement in expression to $\mathrm{CPN}$ of the somatosensory cortex postnatally. We generated progenitor-stage and postmitotic forebrainspecific Cited 2 conditional-null (cKO) mice, using the Emx1-Cre and NEX-Cre mouse lines, respectively. In progenitor-stage cKO, we identify broad reduction of TBR2-positive progenitors at E15.5 across the neocortex, resulting postnatally in both reduced thickness

\footnotetext{
Award Fellowship F31 NS073163 (to R.M.F.); the Eunice Shriver Kennedy National Institute of Child Health and Human Development (NIH R01HD078561, R21HD069001; to E.T.); and a National Health and Medical Research Council Senior Research Fellowship (ID1042002; to S.L.D.). We thankmembers of the Macklis laboratory for thoughtful discussions and input, and Lincoln Pasquina, Ryan Richardson, Ben Noble, and loana Florea for technical assistance. We thank Professor Klaus-Armin Nave (Max Planck Institute of Experimental Medicine, Goettingen, Germany) for generously providing the NEX-Cre mice.

${ }^{*}$ R.M.F. and J.L.M. contributed equally to this work.

The authors declare no competing financial interests.

Correspondence should be addressed to Jeffrey D. Macklis at the above address. E-mail: jeffrey_macklis@harvard.edu.

J. L. MacDonald's present address: Department of Biology, Syracuse University, Syracuse, NY 13244.

DOI:10.1523/JNEUROSCI.4067-15.2016

Copyright $\odot 2016$ the authors $\quad 0270-6474 / 16 / 366404-17 \$ 15.00 / 0$
}

of superficial layers and a highly area-specific reduction of layer II/III somatosensory neocortical length. Importantly, loss of Cited2 function does not disrupt the barrel field, resulting instead in an unprecedented misalignment of molecular areal identity between layers II/ III and IV. Further, we identify area-specific disruption of dendritic complexity and precise axonal connectivity of somatosensory CPN. Cited2 is not required postmitotically for these functions, even though some processes, such as arealization and dendritic arborization, are completed postmitotically. Together, our results demonstrate that Cited 2 functions differently from previously described mechanisms to regulate two stages of precise CPN development, acting in neocortical progenitors to both broadly regulate generation of superficial layer CPN throughout the neocortex and, in an areally restricted manner to refine the distinct identity and precise connectivity of somatosensory CPN. This novel subtype-specific and areaspecific control from progenitor action adds yet another layer of complexity to the multistage development of the neocortex.

\section{Materials and Methods}

Mice. C57BL/6 wild-type (WT) mice were obtained from Charles River Laboratories for retrograde labeling, Western blotting, and determining gene expression. Cited 2 conditional floxed mice (Preis et al., 2006), Lmo4 conditional floxed mice (Deng et al., 2010), and NEX-Cre mice (Goebbels et al., 2006) were previously described. Emx1-Cre mice were generated by Guo et al. (2000) and obtained from The Jackson Laboratory (strain number 005628). To avoid nonspecific cre recombinase activity in oocytes (Hayashi et al., 2003), all cKOs were generated by crossing fl females with fl; cre + males, and no offspring from fl; cre + dams were analyzed. The morning of the day of the appearance of the vaginal plug was defined as E0.5. The day of birth was designated postnatal day (P) 0 . All animal procedures were approved by the Massachusetts General Hospital and/or Harvard University Institutional Animal Care and Use Committees.

In situ hybridization and histology. Postnatal tissue was fixed overnight in $4 \%$ paraformaldehyde (PFA)/PBS at $4^{\circ} \mathrm{C}$; for flatmount analysis, cortices were flattened and fixed $3 \mathrm{~d}$ in $4 \% \mathrm{PFA} / \mathrm{PBS}$ at $4^{\circ} \mathrm{C}$. Fixed tissue was sectioned on a vibrating microtome for in situ hybridization. Embryonic tissue was flash frozen in 2-methyl butane, embedded in TBS, and cryosectioned. In situ hybridization was performed as previously described (Cederquist et al., 2013). The probes were synthesized as described previously: Cited2, Molyneaux et al. (2009); Ror $\beta$, ephrinA5, Allen Brain Atlas Resources (http://www.brain-map.org); EphA7, Mori et al. (1995); Cadh8, Joshi et al. (2008).

Immunocytochemistry and Western blotting. Brains were postfixed overnight in $4 \% \mathrm{PFA} / \mathrm{PBS}$ at $4^{\circ} \mathrm{C}$, then were sectioned on a VT1000S vibrating microtome (Leica Microsystems). Sections were incubated in primary antibody dilutions at $4^{\circ} \mathrm{C}$ overnight, and appropriate secondary antibodies were selected from the Invitrogen Alexa series (Invitrogen). Antigen retrieval methods were required to expose antigens for some of the primary antibodies. Sections were incubated in $0.1 \mathrm{~m}$ citric acid, $\mathrm{pH}$ 6.0 , for $10 \mathrm{~min}$ at $95-98^{\circ} \mathrm{C}$. Primary antibodies were used as follows: goat anti-LMO4 (Santa Cruz Biotechnology SC-11122), rat anti-TBR2 (eBioscience 14-4875), rabbit anti-TBR2 (Abcam ab23345), rabbit anti-PAX6 (Millipore Ab2237), goat anti-BHLHB5 (Santa Cruz Biotechnology SC6045), goat anti-CUX1 (Santa Cruz Biotechnology SC-13024), mouse anti-phosphorylated histone $\mathrm{H} 3$ (pH3; Abcam ab14955), rabbit antipH3 (Millipore 06-570), mouse anti- $\beta$ III tubulin (Covance mms-435P), mouse anti-PCNA (Sigma-Aldrich WH0005111M2), rat anti-CTIP2 (Abcam ab18465), rabbit anti-Ki67 (Abcam ab15580), rabbit-anti ROR $\beta$ (a generous gift from the Stunnenberg laboratory), rabbit anti-5HT (Immunostar 20080), mouse anti-myelin basic protein (MBP; Millipore Bioscience Research Reagents MAB387), and rabbit anti-GFP (Invitrogen A-11122). Immunocytochemistry was performed as previously described (Cederquist et al., 2013).

Immunoblotting was performed as previously described (Macdonald et al., 2010). Briefly, neocortical tissue was isolated, and protein homogenates were separated by $4-20 \%$ SDS-PAGE, and transferred to nitrocel- 
lulose membrane (Bio-Rad Trans-Blot). Membranes were incubated for $12-20 \mathrm{~h}$ at $4^{\circ} \mathrm{C}$ in rabbit anti-CITED2 (Abcam ab108345) primary antibody diluted in $2 \%$ milk/TBS, and developed with goat anti-rabbit HRP IgG (Bio-Rad) diluted in $2 \%$ milk/TBS, and signals were detected with chemiluminescence (Pierce).

Quantification of neocortical length and thickness. All length and thickness measurements were performed with images of matched sagittal 50 $\mu \mathrm{m}$ sections using ImageJ to trace the curvature of the neocortical surface. Areas were delineated using the noted marker gene expression. Deep layers (V, VI) were identified as those including cells expressing high levels of CTIP2 and deeper. Superficial layers (II-IV) were identified as those superficial to high level CTIP2 expression. $P$ values were calculated using the unpaired two-tailed Student's $t$ test using GraphPad Prism for Mac (GraphPad Software, www.graphpad.com). A robust regression outliers (ROUT) test $(Q=0.5 \%)$ was performed for all datasets with an $N \leq 10$ (Motulsky and Brown, 2006). No outliers were discovered.

Golgi staining and dendritic complexity analysis. P22 mouse brains were immersed in freshly prepared impregnation solution (FD Rapid GolgiStain kit, FD Neurosciences), and processed according to the protocol provided by the company. Neurons were imaged, and then traced blinded to genotype. Dendritic complexity was quantified using Sholl analysis (Sholl, 1953) using Image (W. S. Rasband, ImageJ, National Institutes of Health, Bethesda, Maryland) with the Sholl Analysis Plugin (v1.0; Ghosh Laboratory, http://labs.biology.ucsd.edu/ghosh/software/). The following parameters were used for dendrite analysis: step, $10 \mu \mathrm{m}$; beginning radius, $20 \mu \mathrm{m}$; final radius, $200 \mu \mathrm{m}$.

High angular resolution diffusion imaging and tractography reconstruction. Adult ( 9 weeks old) mouse brains were perfused and fixed for an additional week in 4\% PFA solution containing $1 \mathrm{~mm}$ gadolinium MRI contrast agent to reduce the $\mathrm{T} 1$ relaxation time while ensuring that enough T2-weighted signal remained. Brains were then scanned on a 4.7 T Bruker Biospec MR system. The pulse sequence used for high angular resolution diffusion imaging (HARDI) acquisition was a 3D diffusionweighted spin-echo echo-planar imaging sequence (Tuch et al., 2003) with a spatial resolution of $175 \times 175 \times 175 \mu \mathrm{m}, 60$ diffusion-weighted measurements (high $b$ value, $4000 \mathrm{~s} / \mathrm{mm}^{2}$ ). Diffusion Toolkit and TrackVis (http://trackvis.org) were used to reconstruct and visualize tractography pathways that crossed the midline and passed through both the right and left neocortical hemispheres using an angle threshold of $45^{\circ}$. Tractography was initiated from each voxel within the brain mask, which limits the number of streamlines. Rather than use a fractional anisotropy (FA) threshold, brain mask volumes generated from the Diffusion Toolkit were used to terminate tractography pathways, because brain abnormalities can result in low FA values that may potentially incorrectly terminate tractography tracing (Takahashi et al., 2010; Rosen et al., 2013; Song et al., 2015). Streamline length was not limited in the analyses. The regions of interest and exclusion were manually drawn from the MRI. We included all tracts that crossed the midline and passed through both the right and left neocortical hemispheres. Any tract that passed through the anterior commissure was excluded, ensuring that other fiber pathways were not contributing to our analyses.

Anterograde and retrograde axonal labeling. P6 pups were anesthetized by hypothermia, each somatosensory neocortex was injected stereotaxically with a pulled glass micropipette (tip diameter, $80-100 \mu \mathrm{m}$ ), and cell bodies were infected with either adeno-associated virus (AAV)-eGFP (Maguire et al., 2013) or the $\beta$ subunit of cholera toxin (CTB) labeled with Alexa dyes, respectively. Cells were labeled from this boundary area with four tightly clustered injection sites, each consisting of five injections of $4.6 \mathrm{nl}$ each at a depth of $250 \mu \mathrm{m}$. Only brains with matched injections were included in the analysis. Mice were transcardially perfused for analysis at 6 weeks, as outlined previously.

Injection area and contralateral CPN projection spread were analyzed using ImageJ (W.S. Rasband, ImageJ, U.S. National Institutes of Health, Bethesda, Maryland). Fluorescence intensity was measured in a defined box across the injection in a sagittal section. Total pixels were binned in $100 \mu \mathrm{m}$ bins extending rostrally and caudally from the center of the injection. Fluorescence pixel intensity was calculated as a function of distance from the center of injection within superficial layers of both the injected hemisphere of the neocortex and the matched contralateral region. $P$ values for each bin were calculated using the Bonferroni post-test on the unpaired two-tailed Student's $t$ test using GraphPad Prism for Mac. Axonal distribution was divided into three regions (anterior tail: -1400 to $-800 \mu \mathrm{m}$; center: -700 to $700 \mu \mathrm{m}$, and posterior tail: $800-$ $1400 \mu \mathrm{m})$ and two-way ANOVA analysis was performed for each regional distribution using GraphPad Prism for Mac (GraphPad Software, www.graphpad.com). A ROUT test $(Q=0.5 \%)$ was performed for all datasets with $N \leq 10$ (Motulsky and Brown, 2006). No outliers were discovered.

Cell counts and density quantification. E15.5 mouse neocortices were sectioned sagittally and imaged with confocal microscopy at three distinct rostrocaudal positions. Individual cells were quantified based on PAX6, TBR2, and PCNA positivity. Change in basal cell divisions was evaluated by position of $\mathrm{pH} 3$-positive mitotic cells. $P$ values were calculated using the Student's $t$ test. Neocortical cellular density at P3 was measured in matched sagittal $14 \mu \mathrm{m}$ cryosections stained for DAPI to mark nuclei, and immunolabeled for LMO4 and CTIP2 to mark areas and laminae. Boxes of standard width were digitally placed over images, and volume was calculated using $14 \mu \mathrm{m}$ section thickness, measured orthogonal laminar thickness for each sample, and the $280-\mu \mathrm{m}$-wide box; density is expressed as cells $/ 100 \mu \mathrm{m}^{3}$. $P$ values were calculated using the unpaired two-tailed Student's $t$ test. A ROUT test $(Q=0.5 \%)$ was performed for all datasets with $N \leq 10$ (Motulsky and Brown, 2006). No outliers were discovered.

Microscopy and image analysis. Tissue sections were imaged on a Nikon 90i microscope using a 1.5 megapixel cooled CCD digital camera (Andor Technology) or a 5 megapixel color CCD digital camera (Nikon Instruments). Images were collected and analyzed with Elements acquisition software (Nikon Instruments). Laser confocal analysis was performed using a Bio-Rad Radiance 2100 confocal microscope with LaserSharp 2000 imaging software (Bio-Rad Laboratories). Images were processed using a combination of functions provided by Elements analysis software (Nikon Instruments), ImageJ (W.S. Rasband, ImageJ, U. S. National Institutes of Health, Bethesda, Maryland), and Adobe Photoshop/Illustrator software packages (Adobe).

\section{Results}

Cited 2 is expressed in the SVZ at E15.5 and, postnatally, by a restricted population of somatosensory $\mathrm{CPN}$

The transcriptional coregulator Cited $2[\mathrm{CBP} / \mathrm{p} 300$-interacting transactivator with glutamic acid/aspartic acid-rich C-terminal domain 2] is more highly expressed by CPN relative to other cortical projection neuron subpopulations [in particular, corticospinal motor neurons (CSMN)] in the developing neocortex, with peak differential expression at E18.5, the earliest time point at which CPN and CSMN can be purified by retrograde labeling (Molyneaux et al., 2009; Fig. 1A). We confirmed and more broadly investigated the neocortical expression of CITED2 protein by Western blotting from the developing neocortex, revealing high CITED2 expression beginning at E15.5, and decreasing postnatally (Fig. $1 B$ ). In situ hybridization reveals that there is minimal pallial expression of Cited 2 at E13.5, but Cited2 is highly expressed in progenitor regions throughout the SVZ of the developing neocortex during superficial layer CPN generation at E15.5 (Fig. 1C,D), with expression decreasing as differentiation proceeds. Postnatally, total expression levels of Cited2 decrease, and its neocortical expression strikingly refines to layers II/III, V, and VI of somatosensory areas, mirroring the laminar distribution of CPN (Fig. 1E,F). To further investigate this refinement of Cited 2 expression, we examined Cited 2 expression in sagittal preparations (Fig. 1G,H). Embryonically, Cited2 is expressed across the rostrocaudal extent of the neocortex (Fig. 1G). Postnatally, Cited 2 expression becomes progressively restricted to CPN (in layers II/III, V, and VI) of the somatosensory neocortex by P3, in keeping with the known refinement of molecular areal boundar- 
ies (Fig. $1 H$ ). This broad early SVZ progenitor expression across areas, with postnatal areal refinement to somatosensory CPN, led us to hypothesize two stages of function for Cited2 in neocortical, and specifically CPN, development: broadly, in generation of superficial layers, and area-specifically, in maturation of somatosensory CPN.

The SVZ is largely composed of intermediate progenitor cells (IPCs; or basal progenitors), which are transitamplifying progenitors that arise from asymmetric divisions of radial glial cells (RGCs) of the VZ, and which undergo a limited number of symmetric divisions before generating pairs of postmitotic neurons (Haubensak et al., 2004; Miyata et al., 2004; Noctor et al., 2004). Although IPCs give rise to projection neurons of all laminae, at E15.5, the peak of Cited2 expression, they largely generate superficial layer projection neurons (Sessa et al., 2008; Kowalczyk et al., 2009), of which CPN are the predominant population. The high Cited2 expression throughout the SVZ suggests a potential Cited2 function in IPCs at E15.5. At E15.5, Cited2 is most highly expressed in the laminar domain that overlaps with TBR2-expressing (TBR2+) IPCs of the SVZ, extending into the early postmitotic neurons of the intermediate zone, but it is mostly excluded from the region containing PAX6+ RGCs of the VZ (Fig. $1 I, J)$. The SVZ region expressing Cited 2 includes both proliferating and nonproliferating populations, as assessed by the mitotic markers Ki67 and pH3 (Fig. $1 I, K$ ). Together, these data suggest that CITED2 functions in SVZ IPCs as they transition from cycling progenitors to postmitotic neurons across all areal anlagen at E15.5, when superficial neocortical neurons are being generated.

Cited 2 controls TBR2+ IPC number and proliferation in the E15.5 neocortex

To investigate developmental requirements for Cited 2 in neocortical generation and precise CPN maturation, we generated mice null for Cited 2 in the neocortex. To bypass a set of early patterning defects in homozygous Cited2-null mutants (Bamforth et al., 2001), and any confounding role Cited 2 might have in the subpallial domain, we generated pallial cortex-specific cKOs using Emxl-promoter driven cre-recombinase (Emx1-Cre; Guo et al., 2000; Jin et al., 2000). In all experiments, we compared Cited $2^{f l / f l} ;$ Emx1-Cre+ cKO mice to littermate controls, both Cited $2^{\text {fllfl }} ; \mathrm{Em} \times 1$ 1-Cre - and $\mathrm{Cited2}^{\mathrm{fl} /+}$; Emx1-Cre+. Because no significant differences were observed between the two control genotypes, they were combined as Cited 2 WT in analyses. We verified that these cKO mu-
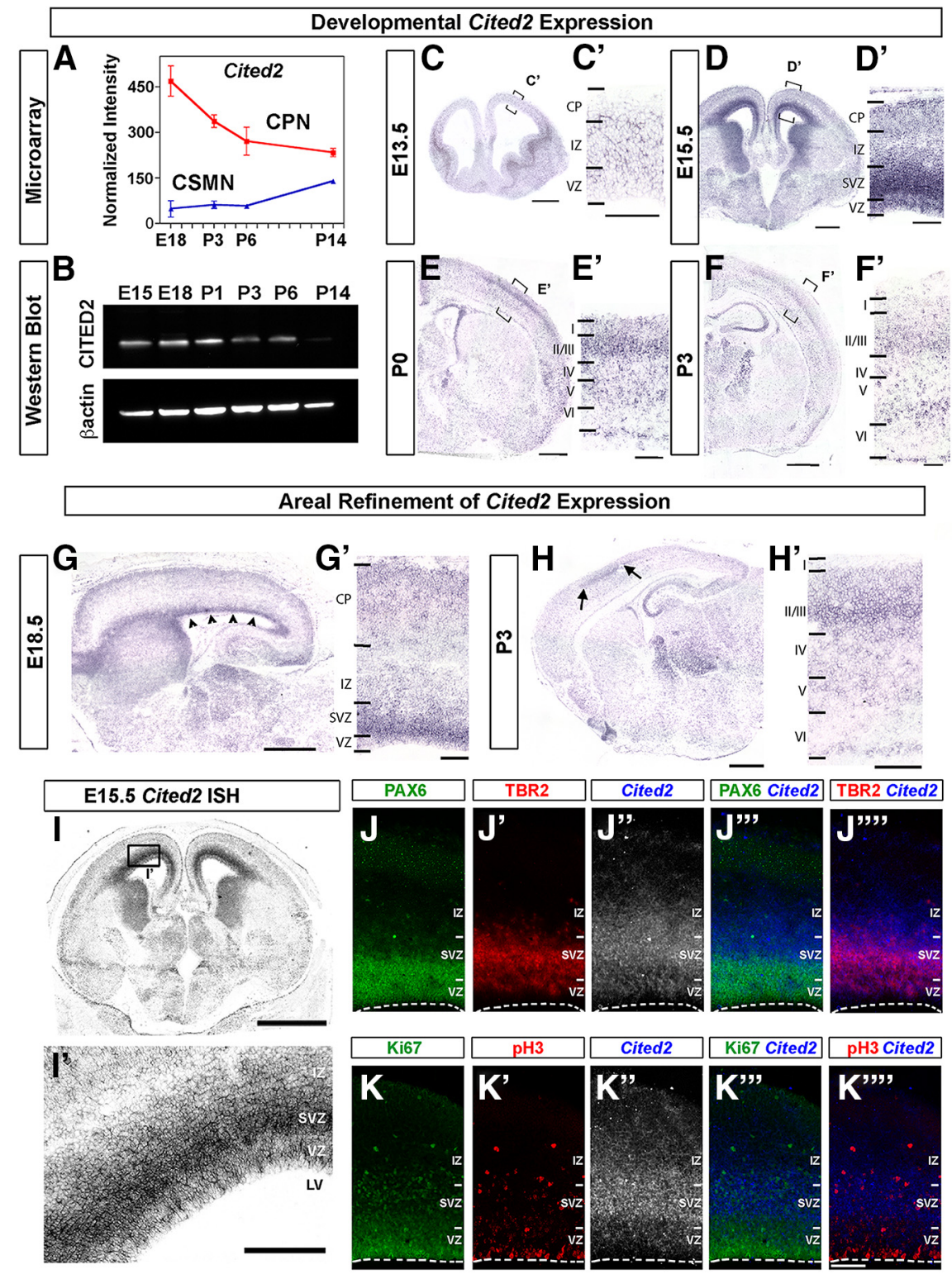

Figure 1. Cited 2 is expressed broadly by CPN progenitors at E15.5, with expression refining to CPN of the somatosensory cortex by P3. $\boldsymbol{A}$, Cited2 is highly expressed by CPN (red) relative to CSMN (blue) at critical times during development, as detected by microarray analysis of FACS-purified CPN and CSMN. Error bars denote SEM (Molyneaux et al., 2009). $\boldsymbol{B}$, Western blot analysis showing that CITED2 protein is highly expressed as early as E15.5 in the neocortex, with expression decreasing postnatally, relative to a $\beta$-actin loading control. $\boldsymbol{C}-\boldsymbol{F}$, Expression of Cited 2 is largely restricted to subpallial progenitors at E13.5 $(\boldsymbol{C})$, but Cited2 is highly expressed in the cortical SVZ at E15.5 (D), the peak of superficial layer CPN birth, with expression maintained in layers II/III and V postnatally $(\boldsymbol{E}, \boldsymbol{F}) . \boldsymbol{G}$, Embryonically, Cited2 is expressed uniformly across the neocortex, detected across the SVZ at E18.5 (arrowheads) and across the cortical plate (CP). $\boldsymbol{H}$, In the first days postnatally, however, its expression refines and becomes restricted to somatosensory cortex (arrows) by P3. I, At E15.5, Cited 2 is highly expressed in the SVZ, extending into the intermediate zone (IZ). J, Cited 2 (blue) is largely excluded from PAX6 + (green) radial glial progenitors of the VZ, but is highly expressed by TBR2 + (red) IPCS of the SVZ. $K$, Cited 2 is largely excluded from the highly proliferative Ki67 + (green) VZ and apical mitotic cells, as indicated by pH3 (red), but is expressed by basally proliferating IPCs of the SVZ and IZ. Scale bars: $\boldsymbol{C}-\boldsymbol{F}, 500 \mu \mathrm{m} ; \boldsymbol{G}-\boldsymbol{I}, 1 \mathrm{~mm} ; \boldsymbol{C}^{\prime}-\boldsymbol{H}^{\prime}, \boldsymbol{J}, \boldsymbol{K}, 100 \mu \mathrm{m} ; \boldsymbol{I}^{\prime}, 200 \mu \mathrm{m}$. Dotted lines in $\boldsymbol{J}$ and $\boldsymbol{K}$ indicate apical, ventricular surface.

tants are viable and healthy, and confirmed that early cortical neurogenesis, preceding onset of pallial Cited 2 expression, is not affected in Cited 2 cKO brains, as assessed by VZ (Cited2 WT, $2694 \pm 36 \mu \mathrm{m}$; Cited $2 \mathrm{cKO}, 2683 \pm 56 \mu \mathrm{m} ; N=10 \mathrm{WT}$ and 5 $\mathrm{cKO}, p=0.87)$ and cortical plate length (Cited $2 \mathrm{WT}, 3163 \pm 33$ $\mu \mathrm{m}$; Cited $2 \mathrm{cKO}, 3093 \pm 75 \mu \mathrm{m} ; p=0.33)$ and thickness at E15.5 across the rostrocaudal axis (medial: Cited2 WT, $317 \pm 6 \mu \mathrm{m}$; Cited $2 \mathrm{cKO}, 297 \pm 12 \mu \mathrm{m} ; p=0.12$ ). 

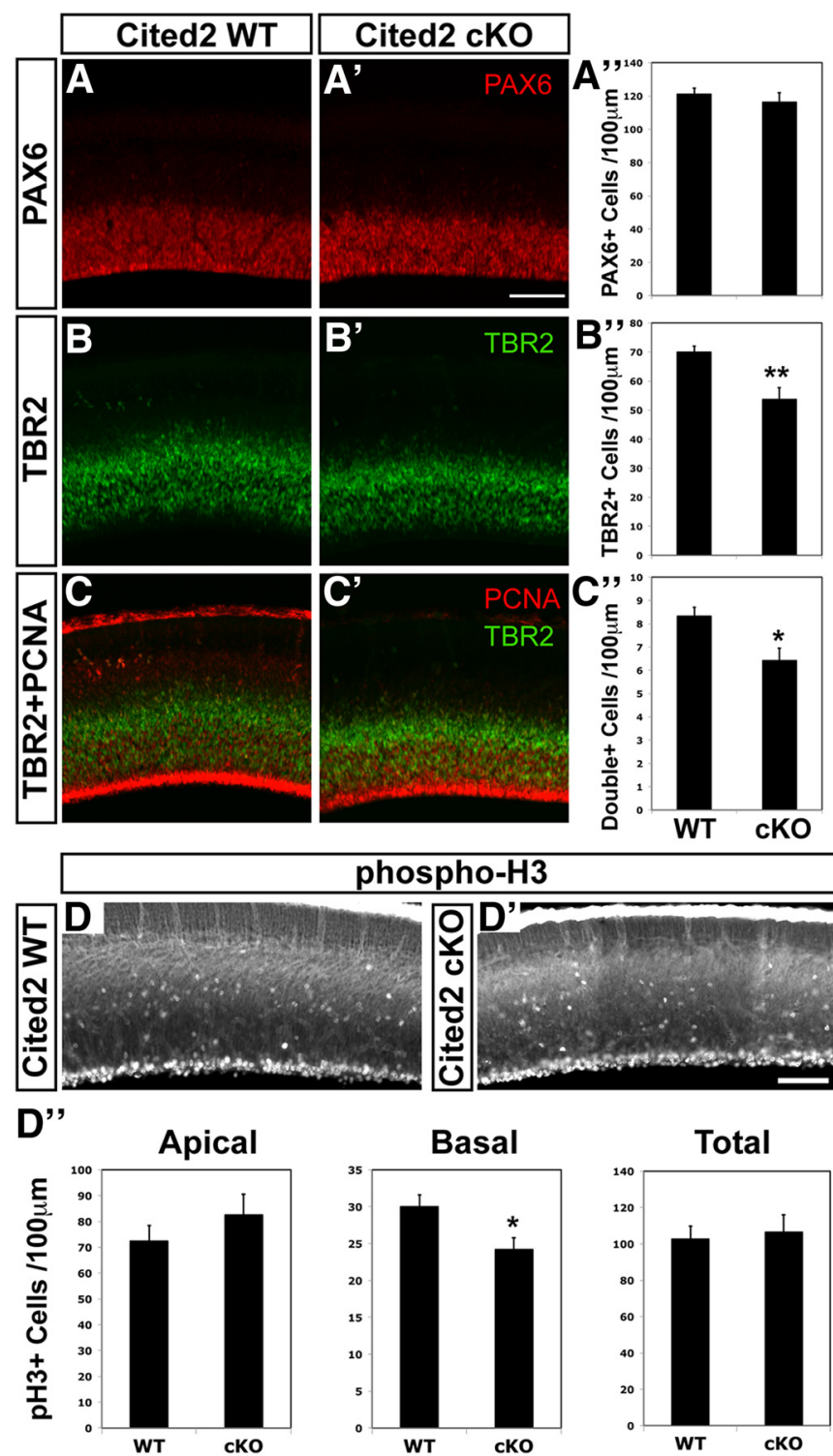

\section{$\mathbf{F}$}

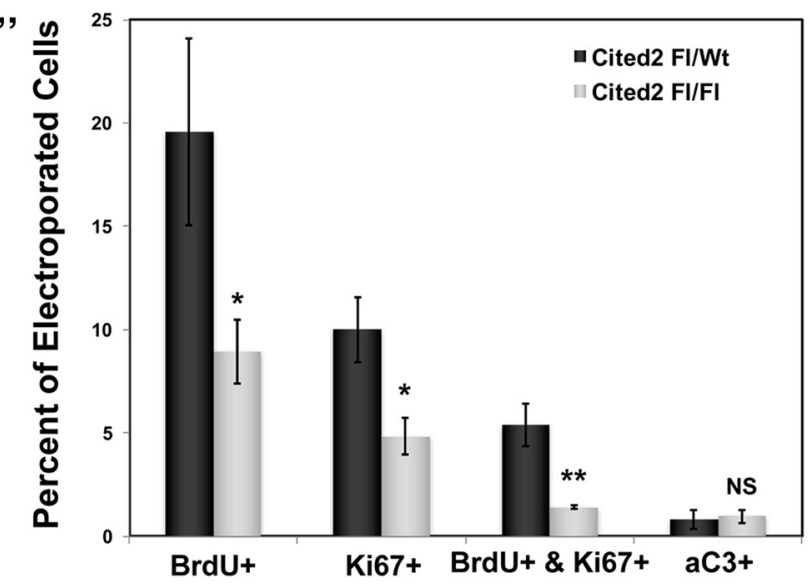

Figure 2. Loss of Cited2 function results in specific reduction of TBR2 + IPCs in the E15.5 neocortex. $A-A^{\prime \prime}, A t E 15.5$, the peak of Cited2 expression, there is no change in the overall number of $(P A X 6+)$ radial glial progenitors in the Cited2;Emx1-Cre CK0 neocortex compared with control littermates (WT). $\boldsymbol{B}-\boldsymbol{B}^{\prime \prime}$, There is, however, a significant reduction in the number of TBR2 + IPCS, which largely give rise to superficial layer (PN at this stage of development. $C-\boldsymbol{D}^{\prime \prime}$, Reduction in TBR2 + IPCs might result from reduced proliferation of IPCs $\left(\boldsymbol{C}-\boldsymbol{C}^{\prime \prime}\right)$, as indicated by proliferating cell nuclear antigen (PCNA, red) and TBR2 (green) double positivity ( $N=11$ WT, 6 cKO for $\boldsymbol{A}-\boldsymbol{C}$; ; specific reduction in basal cell divisions $\left(\boldsymbol{D}-\boldsymbol{D}^{\prime}\right)$, as indicated by position of pH3-positive mitotic cells $(N=10$ WT, 5 CKO); and/or increased cell death (E), as indicated by expression of aC3. There is increased apoptotic cell death in the Cited 2 cK0 neocortex, both within the progenitor population and postmitotically ( $N=11 \mathrm{WT}, 6 \mathrm{cKO})$. $\boldsymbol{F}-\boldsymbol{F}^{\prime \prime}$, To directly investigate whether Cited2 cell-autonomously regulates proliferation of IPCs, we electroporated Cre recombinase and GFP into VZ progenitors of Cited $2^{f / f f}$ and Cited $2^{f / w t}$ littermates at E14.5 to excise Cited2 in a small subpopulation of neocortical progenitors. We used a BrdU pulse at E15.5, and immunocytochemistry for Ki67 at E16.5 to identify progenitors that continued to proliferate. There is a significant reduction in the number of Cited2-null (Cited2 ${ }^{f / f f}$; (re +) progenitors that incorporate BrdU at E15.5, or express Ki67 + at E16.5, demonstrating that Cited2-null IPCs are less likely to re-enter the cell cycle than their heterozygous counterparts. There is no change in the number of aC $3+$ cells in the Cited2-null progenitors at E16.5 ( $N=4$ (ited2 $^{f / w t} ; 5$ (ited $\left.2^{f / f}\right)$. Scale bars, $100 \mu \mathrm{m}$. Error bars denote SEM. ${ }^{*} p<0.05 ;{ }^{* *} p<0.001$ (Student's $t$ test).

Because Cited 2 is highly expressed throughout the SVZ at E15.5, we specifically investigated whether the population of TBR2 + IPCs is altered in the absence of Cited 2 function. In the setting of a broadly well patterned and laminated E15.5 neocortex, there is a highly specific $\sim 20 \%$ reduction of TBR $2+$ IPCs in Cited 2 cKO mice (Fig. 2B), while the number of PAX6+ RGCs is not altered (Fig. 2A). At this age, only a small fraction of TBR2+ IPCs are actively proliferating, as assessed by PCNA; however, there is a significant decrease in the number of PCNA+ IPCs in Cited $2 \mathrm{cKO}$ mice (Fig. 2C). The total number of PCNA+ cells, largely PAX6 + RGCs, is not altered in Cited $2 \mathrm{cKO}$ mice (Cited2 WT, $115 \pm 2$ PCNA + cells $/ 100 \mu \mathrm{m}$; Cited $2 \mathrm{cKO}, 113 \pm 2$
PCNA+ cells $/ 100 \mu \mathrm{m} ; N=10 \mathrm{WT}$ and $6 \mathrm{cKO}, p=0.67)$. We directly investigated the population of actively proliferating IPCs as basal mitotic $\mathrm{pH} 3+$ progenitors (Fig. $2 D$ ). While there is not a general disruption in mitotic progenitors, there is a specific reduction in basally located mitotic progenitors, indicating a specific requirement for Cited 2 in IPC proliferation, but not in RGC proliferation.

In addition to perturbed proliferation, a reduction in TBR2+ IPCs might also result from cell death. We directly investigated this possibility by assessing apoptosis at E15.5 using activated caspase $3(\mathrm{aC} 3+)$. We identified a significant increase in aC3+ cells in the Cited 2 cKO neocortex, in both proliferating progeni- 
tors (PCNA+) and postmitotic neurons (PCNA-) (Fig. 2E). This significant increase in apoptosis among progenitors likely contributes to the substantial decrease in TBR2+ progenitors in the Cited 2 cKO neocortex.

The reduction in PCNA+/TBR2+ IPCs and basally located mitotic progenitors in the Cited $2 \mathrm{cKO}$ neocortex suggests that Cited 2 is necessary for expansion of the IPC population. To directly investigate whether Cited 2 cell-autonomously regulates proliferation of IPCs, we electroporated Cre recombinase into progenitors of Cited $2^{f l / f l}$ and Cited $2^{f l / w t}$ littermates at E14.5, to excise Cited 2 in a small subpopulation of neocortical progenitors. We coelectroporated GFP to identify progenitors that were cycling at E14.5 and were electroporated, and we used a BrdU pulse at E15.5 and immunocytochemistry for Ki67 at E16.5 to identify progenitors that continued to proliferate (Fig. $\left.2 F-F^{\prime \prime \prime}\right)$. We identified a significant reduction both in the number of Cited2-null (Cited $2^{f l / f l}$; Cre + ) progenitors that incorporated BrdU at E15.5 and in the number of Cited2-null (Cited2 $2^{f l f l}$; Cre + ) progenitors that were Ki67+ at E16.5. Further, there was a significant reduction in the number of cells proliferating at E15.5 that were still cycling at E16.5 (BrdU/Ki67 double positive). Additionally, we used immunocytochemistry for aC3 at E16.5, and did not identify a significant change in the number of Cited2-null (Cited $2^{f l / f l}$; $\mathrm{Cre}+$ ) progenitors that were dying at E16.5. These analyses demonstrate that Cited2-null IPCs are less likely to re-enter the cell cycle than their heterozygous counterparts, further supporting the conclusion that Cited 2 cell-autonomously contributes to regulation of IPC proliferation, and that this reduction in basal progenitor proliferation contributes to the reduction in TBR2+ progenitors in the Cited $2 \mathrm{cKO}$ neocortex at E15.5.

The later areal refinement of Cited 2 expression raises the hypothesis that CITED2 function in the SVZ is areally restricted based on overlapping, intersectional expression of coregulators. For example, the known CITED2 interactor AP2 $\gamma$ (Bamforth et al., 2001) is broadly expressed across the VZ; however, it regulates specification of TBR2 + IPCs and generation of superficial layers only in the occipital cortex (Pinto et al., 2009), presumably through an area-restricted coregulator. To investigate whether Cited 2 functions in an areally restricted manner within SVZ progenitors, we analyzed IPC numbers in three presumptive areal regions, and determined that the progenitor abnormality is uniform across the extent of the developing neocortex (Tbr2 + cells/ $100 \mu \mathrm{m}$ : rostral: $\mathrm{WT}, 76.7 \pm 1.6 ; \mathrm{cKO}, 61.7 \pm 3.4, p=0.0004$; medial: WT, $69.5 \pm 1.9 ; \mathrm{cKO}, 52.2 \pm 3.7, p=0.0003$; caudal: WT, $63.7 \pm 2.9 ; \mathrm{cKO}, 47.3 \pm 5.5, N=10 \mathrm{WT}$ and $6 \mathrm{cKO}, p=0.01$ Student's $t$ test;), indicating that the function of Cited 2 in IPC proliferation and survival is not areally restricted.

\section{Cited 2 regulates neocortical size, including superficial layer thickness and neocortical surface length}

Superficial layer CPN arise predominantly from IPCs (Sessa et al., 2008; Kowalczyk et al., 2009); therefore, we investigated whether this significant, broad reduction of IPCs in the Cited2-null neocortex at E15.5 causes a reduction in superficial layer CPN, presenting as a change either radially in thickness of the superficial layers and/or tangentially in the cortical length. Cited 2 is not required for gross neocortical development or laminar organization. At P6, the Cited $2 \mathrm{cKO}$ neocortex is smaller than those of WT littermate controls, but both CPN (SATB2+) and CSMN $(\mathrm{CTIP} 2+)$ are present and appropriately positioned (Fig. $3 A$ ). Anterograde labeling with DiI and retrograde labeling with fluorescently conjugated CTB demonstrate that CPN are present and are appropriately targeting axons to the contralateral hemisphere in the Cited $2 \mathrm{cKO}$ neocortex (Fig. $3 \mathrm{~B}, \mathrm{C}$ ). However, both the distribution of retrogradely labeled $\mathrm{CPN}$ (Fig. $3 C$ ) and CUX1 and CTIP2 immunocytochemistry (Fig. 3D) indicate that superficial layers are thinner in the Cited $2 \mathrm{cKO}$ cortex, while the thickness of deep layers is unchanged.

Quantitative analysis of neocortical layer thickness at P3 reveals a significant $\sim 20 \%$ reduction in superficial layer thickness (layers II/ III and IV, as delineated as cells superficial to CTIP2 expression) across multiple neocortical areas, including the rostral motor cortex, the primary somatosensory area, and the caudal visual cortex. There is no significant change in deep layer thickness (layers V and VI) in any region where CPN account for only a minority of projection neurons (Fig. 3E). To directly investigate whether the reduced superficial layer thickness identified in the Cited $2 \mathrm{cKO}$ neocortex is due to reduced cell number and/or increased cell packing, we quantified cell density within the reduced superficial layers. There is no significant difference in cell density in layers II/III of the motor or visual cortices, and a modest, but significant, increase in cell density in layer II/III of the somatosensory cortex, where the greatest reduction in thickness is observed (motor: Cited2 WT, $369 \pm 128$ cells $/ 100 \mu \mathrm{m}^{3}$; Cited $2 \mathrm{cKO}, 462 \pm 30$ cells $/ 100 \mu \mathrm{m}^{3} ; p=0.44$; somatosensory: Cited 2 WT, $652 \pm 66$ cells $/ 100 \mu \mathrm{m}^{3} ;$ Cited $2 \mathrm{cKO}, 803 \pm 26$ cells $/ 100$ $\mu \mathrm{m}^{3} ; p=0.01$; visual: Cited2 WT, $590 \pm 35$ cells $/ 100 \mu \mathrm{m}^{3}$; Cited2 cKO, $608 \pm 7$ cells $/ 100 \mu \mathrm{m}^{3} ; p=0.55 ; N=6 \mathrm{WT}$ and $\left.3 \mathrm{cKO}\right)$. Additionally, the reduction in superficial laminar thickness in the Cited 2 cKO neocortex persists at P6 (Fig. 3D) and into adulthood. These data indicate that the reduction in the number of TBR2 + IPCs observed early in the development of the Cited2-null neocortex results in a significant reduction in the number of superficial layer $\mathrm{CPN}$ throughout the neocortex. Interestingly, the findings regarding cell density indicate a further area-specific requirement for Cited 2 in development of layer II/III neurons of the somatosensory neocortex.

In addition to the observed reduction in radial thickness in the Cited $2 \mathrm{cKO}$ neocortex, early loss of TBR $2+$ progenitors might also result in an overall decrease in neocortical length on the tangential axis (Sessa et al., 2008; Kowalczyk et al., 2009; Tuoc et al., 2013). We measured cortical surface length at P3, identifying an $\sim 5 \%$ smaller diagonal cortical length, and an $\sim 10 \%$ reduction in rostrocaudal neocortical surface length in the P3 Cited2 cKO neocortex, measured across multiple mediolateral sagittal sections (Fig. $3 F, G$ ). These data indicate that there is both a significant reduction in cortical thickness as a result of Cited 2 loss of function and a significant reduction in neocortical tangential length. This reduction of cortical length does not normalize over time; at P21, the Cited 2 cKO neocortex is still significantly shorter than that of WT littermates (Cited2 cKO normalized to Cited2 WT littermates, $90.9 \pm 3 \%$ neocortical length; $p=0.005, N=6$ WT and $3 \mathrm{cKO}$ ), indicating that the reduction is not simply a delay in maturation, but rather a persistent reduction of $\sim 10 \%$ of the neocortical rostrocaudal surface length.

\section{Cited 2 refines the boundary of areal molecular identity of layer II/III somatosensory CPN}

Progressive postmitotic refinement of Cited2 expression to the somatosensory cortex led us to hypothesize that CITED2 might have a second phase of function in areal specification of CPN. Dual functions of Cited 2 have previously been identified in eye development, in which Cited 2 acts upstream of Pax6 to regulate lens morphogenesis, and negatively regulates HIF-1 signaling to regulate hyaloid vasculature formation (Chen et al., 2008). Therefore, we assessed whether specification and development of somatosensory $\mathrm{CPN}$ are specifically disrupted in the Cited $2 \mathrm{cKO}$ 

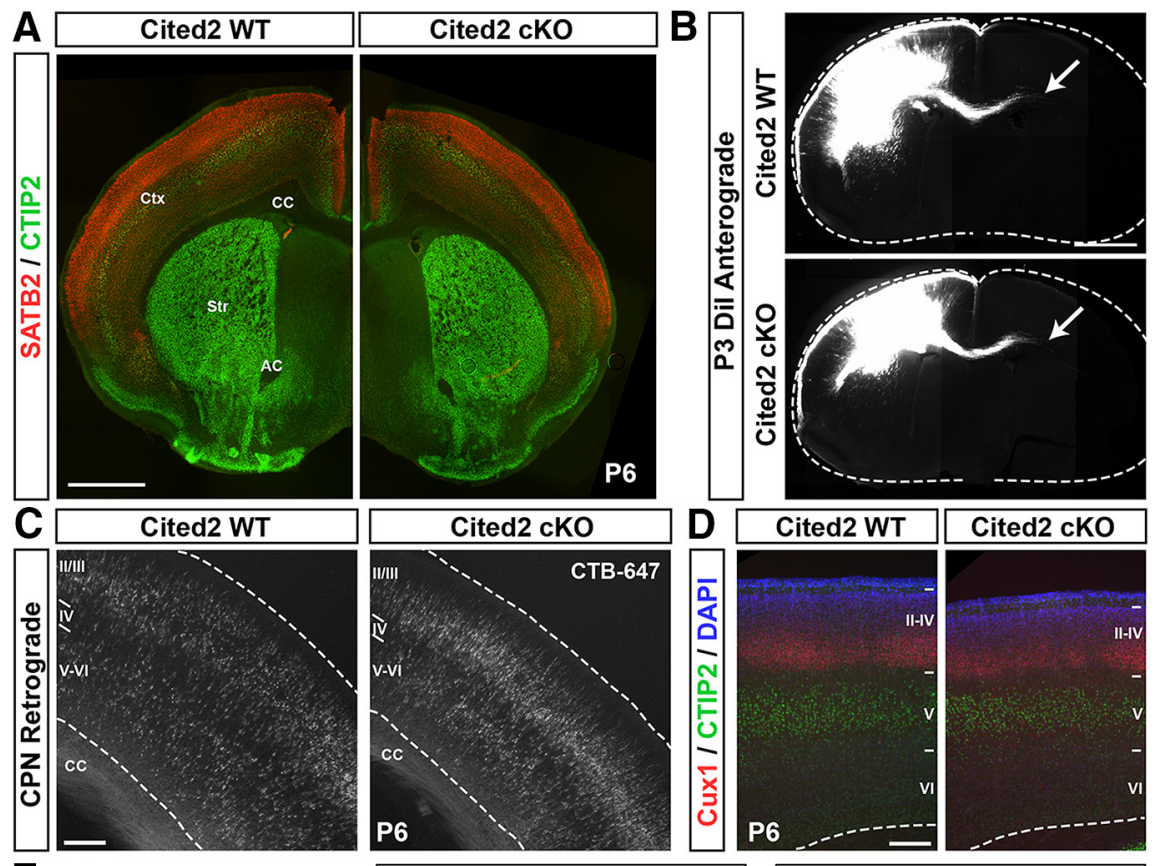

E
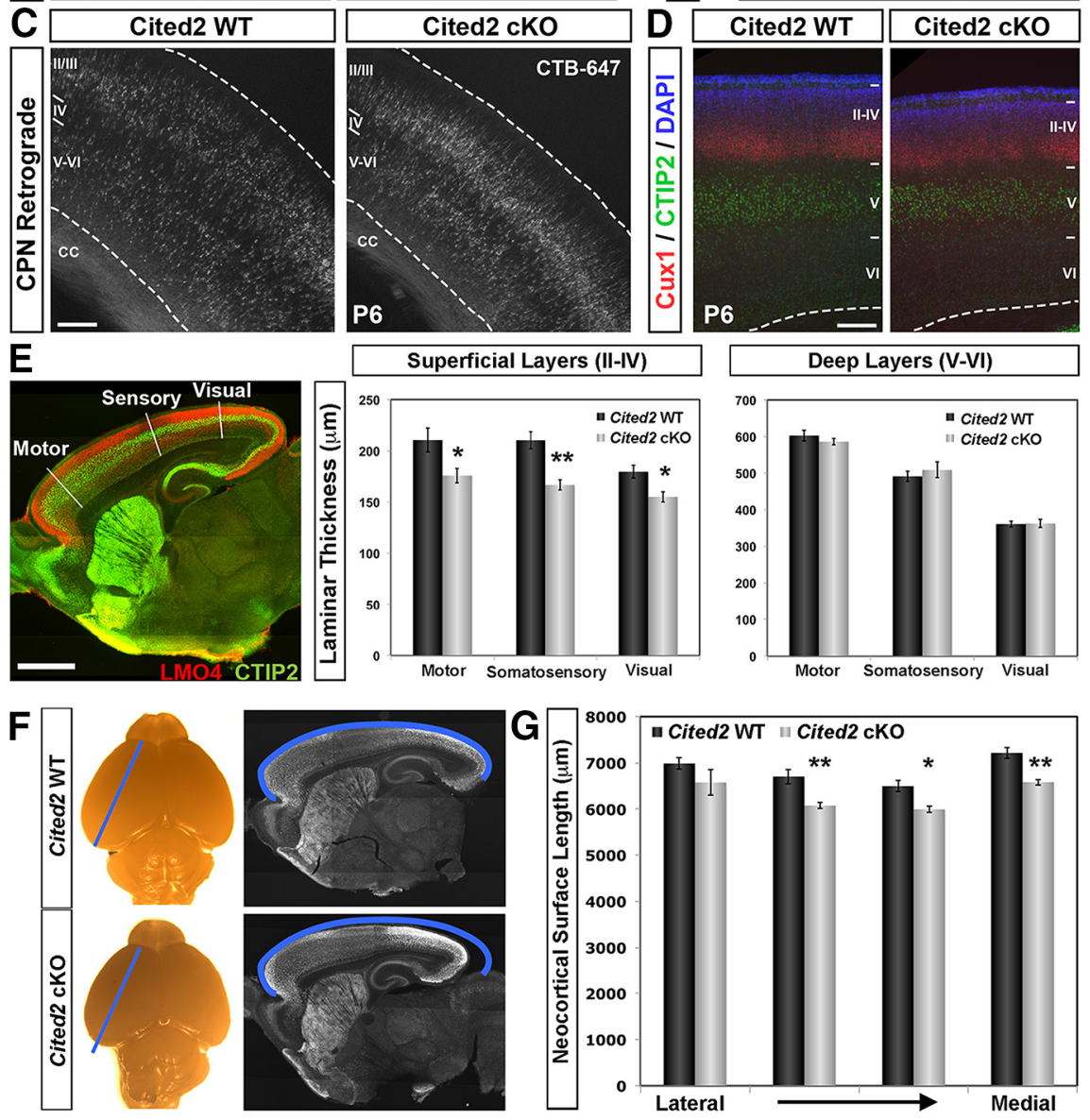

Figure 3. Loss of Cited 2 function results in reduced superficial layer thickness and total neocortical length at P3. $A, A t P 6$, the Cited2 cK0 neocortex is smaller than in WT littermate controls, but both CPN $($ SATB2 +$)$ and CSMN $(C T I P 2+)$ are present and appropriately positioned. $\boldsymbol{B}, \boldsymbol{C}$, Anterograde labeling with $\mathrm{Dil}(\boldsymbol{B})$ and retrograde labeling with $\mathrm{CTB}(\boldsymbol{C})$ demonstrate that CPN are present and are targeting the contralateral hemisphere in the Cited2 cK0 neocortex. However, both the distribution of retrogradely labeled CPN ( $C$ and CUX1 (red, superficial layers) and CTIP2 (green, deep layers) immunocytochemistry (D) indicate that superficial layers are thinner in the Cited 2 CK0 neocortex, while the thickness of deep layers is unchanged ( $N=4-5$ per genotype for $\boldsymbol{A}-\boldsymbol{D})$. $\boldsymbol{E}$, Quantitative analysis of neocortical layer thickness at P3 reveals that superficial layers (II-IV; LM04, red) are significantly thinner in motor, somatosensory, and visual neocortical areas of P3 Cited2 $\mathrm{CKO}$ mice compared with those of control littermates. There is no change in deep-layer thickness (V, VI; CTIP2, green) in any region ( $=8 \mathrm{WT}, 4 \mathrm{CKO})$. $\boldsymbol{F}$, The Cited2 cK0 cortex is visibly smaller than control littermates at $\mathrm{P} 3$, both in wholemount view and in sagittal sections. $\mathbf{G}$, There is a significant reduction in total neocortical surface rostrocaudal length of $\sim 10 \%$, as measured on four sagittal sections across the mediolateral axis ( $N=8 \mathrm{WT}, 4$ cKO). Scale bars: $\boldsymbol{A}, 1 \mathrm{~mm} ; \boldsymbol{B}, 50 \mu \mathrm{m}$. Error bars denote SEM. ${ }^{*} p<0.05 ;{ }^{* *} p<0.001$ (Student's $t$ test).

neocortex, beyond the broad reduction in IPCs and superficial layer generation. First, we investigated whether all neocortical areas are uniformly reduced in the Cited 2 cKO neocortex, or whether the cortical length reduction is areally restricted.

Strikingly, analysis based on three broad cortical areas distinguished by LMO4 expression at P3 (Joshi et al., 2008) indi- cates that there is a highly specific and substantial $(\sim 35 \%)$ reduction in the rostrocaudal length of the somatosensory cortex in Cited $2 \mathrm{cKO}$ mice versus no significant change in the motor or caudal cortex (Fig. $4 A-C$ ). A similar reduction in the somatosensory cortex is observed by expression of BHLHB5 (Fig. 5F,H), which has a largely complementary expression to LMO4, and is highly expressed by CPN of the somatosensory neocortex (Joshi et al., 2008; Cederquist et al., 2013). Thus, the entire $10 \%$ neocortical tangential length reduction occurs in the somatosensory region in which Cited 2 is normally expressed postnatally.

Because Cited2 expression progressively refines to CPN of the somatosensory cortex during the first postnatal days, we investigated when the area-specific function of Cited 2 arises. At P0, before motor and somatosensory cortical areas are fully refined, there is a reduction in both motor and somatosensory cortical lengths, as delineated by LMO4 immunostaining (cKO relative length: motor, $0.89 \pm 0.04, p=0.037$; somatosensory, $0.83 \pm 0.047, p=0.018$; visual, $0.99 \pm$ $0.046, N=6 \mathrm{WT}$ and $3 \mathrm{cKO}, p=0.89$, Student's $t$ test). The reduction in Cited 2 cKO cortical length progressively becomes restricted to the somatosensory cortex by $\mathrm{P} 3$ (cKO relative length: motor, $0.94 \pm 0.046, p=0.13$; somatosensory, $0.64 \pm 0.13, p=0.0005$; visual, $1.02 \pm$ $0.029, N=8 \mathrm{WT}$ and $4 \mathrm{cKO}, p=0.32$, Student's $t$ test) as WT expression of Cited 2 becomes restricted to the somatosensory cortex; this specificity for Cited 2 function in the somatosensory cortex is maintained at $\mathrm{P} 8$ (cKO relative length: somatosensory, $0.73 \pm 0.06 ; N=10 \mathrm{WT}$ and $5 \mathrm{cKO}, p<0.0001$, Student's $t$ test).

We confirmed the somatosensoryspecific reduction of cortical length in $\mathrm{P} 3$ Cited $2 \mathrm{cKO}$ mice using the expression of multiple overlapping and/or complementary molecular markers that, in combination, delineate cortical areas at P3 (Dye et al., 2011). Strikingly, layer II/III measurements of somatosensory cortex length by Cadh 8 , EphrinA5, and EphA7 expression confirm the reduced length observed with LMO4 measurements (Fig. $4 D-F$ ). Consistent with the CPN subtype-specific expression of Cited2, this areal-specific reduction is also layer specific, with no significant difference in length of acallosal layer IV, by expression of EphrinA5 and Ror $\beta$ in somatosensory cortex in Cited 2 cKO mice (Fig. $4 F, G$ ). In addition, loss of Cited 2 function does not disrupt somatosensory barrel morphology, size, or placement (data not shown). 
These results indicate highly specific and significant disruption of layer II/III somatosensory cortex in the absence of Cited2 function. Together, these data suggest that Cited 2 is selectively necessary for acquisition of molecular areal identity of layer II/III somatosensory $\mathrm{CPN}$, but not generally for somatosensory neocortical arealization. In the P3 WT neocortex, molecular markers of the layer IV primary somatosensory cortex (e.g., $\operatorname{Ror} \beta$ ) and the layer II/III somatosensory neocortex (e.g., BHLHB5) align to indicate the boundary between motor and somatosensory cortices (Fig. $\left.4 H-H^{\prime \prime \prime}\right)$. Notably, upon loss of Cited 2 function, the rostral boundary of $\operatorname{Ror} \beta$ expression is no longer aligned with BHLHB5 expression, (Fig. $4 I-I^{\prime \prime \prime}$ ), but rather extends further in the rostral direction than the molecularly identified somatosensory region in layer II/III, indicating an unprecedented misalignment of molecular areal identity between layer II/III and layer IV in the Cited 2 cKO neocortex. This neuronal subtype-specific areal misalignment could result in columnar wiring irregularities, the functional consequences of which would be intriguing to investigate.

\section{Cited 2 and Lmo4 cooperatively control CPN areal identity}

The above evidence indicates functions for Cited2 in specific acquisition of somatosensory CPN identity, leading to the hypothesis that Cited 2 might act as part of a molecular network to generate neuronal areal identity; additional molecular controls might function in acquisition of other CPN areal identities, interacting with Cited 2 at the boundaries to define these subpopulations. Lmo4 is a particularly compelling candidate to function in $\mathrm{CPN}$ of the motor cortex, and to interact with Cited2 at the motor-somatosensory cortex boundary. Lmo 4 has reciprocal areal expression in the neocortex compared with Cited2, and has been shown to have areally restricted roles in neocortical projection neuron subtype identities and connectivity (Kashani et al., 2006; Joshi et al., 2008; Lee et al., 2008; Azim et al., 2009; Huang et al., 2009; Cederquist et al., 2013). Cited 2 interacts genetically with Lmo4, and Lmo 4 can partially functionally compensate for Cited 2 in thymus development (Michell et al., 2010). This knowledge led us to hypothesize that Lmo4 might be performing a parallel, areal-specific function in motor cortex CPN, intersecting with Cited 2 in areal boundary regions. Its maintained expression in the motor cortex might underlie some of the CPN areal differences observed with Cited 2 loss of function.
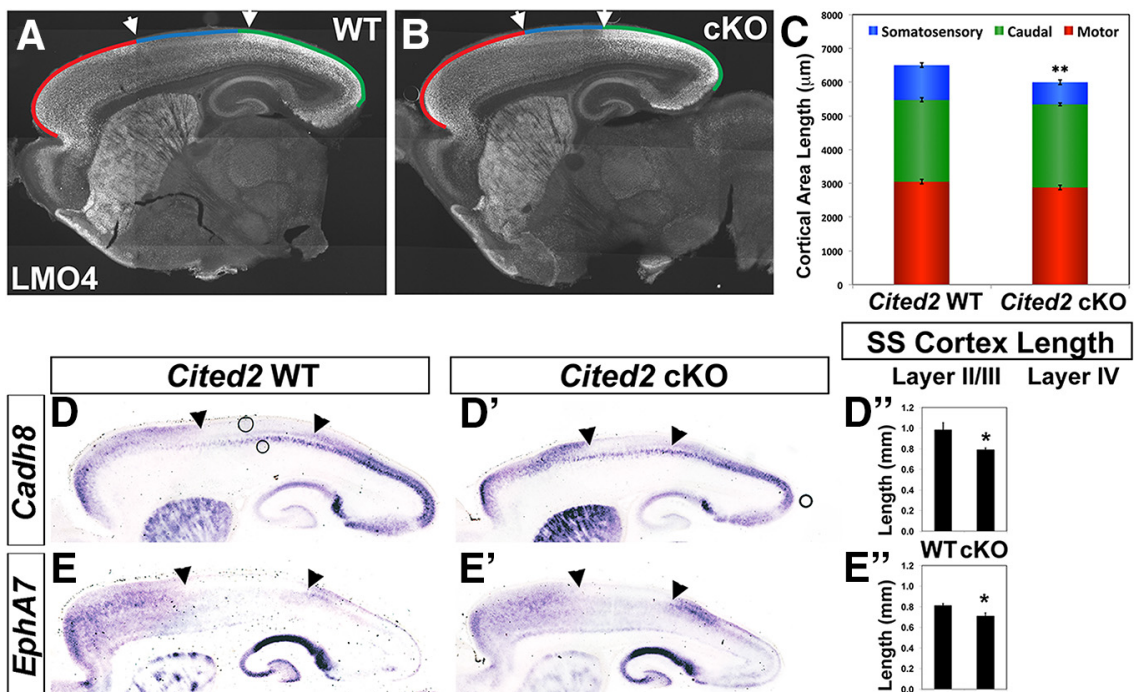

SS Cortex Length
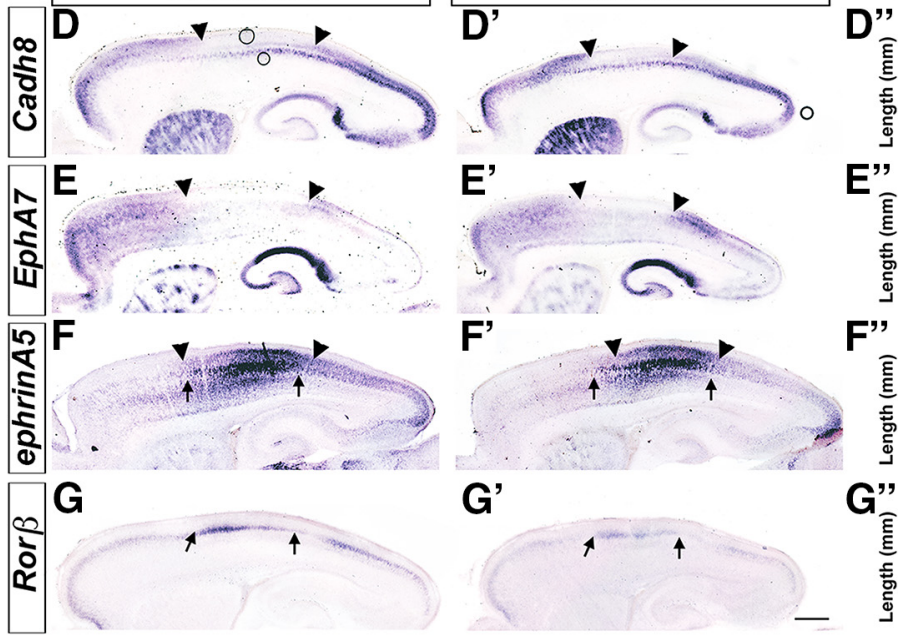

Layer II/III Layer IV
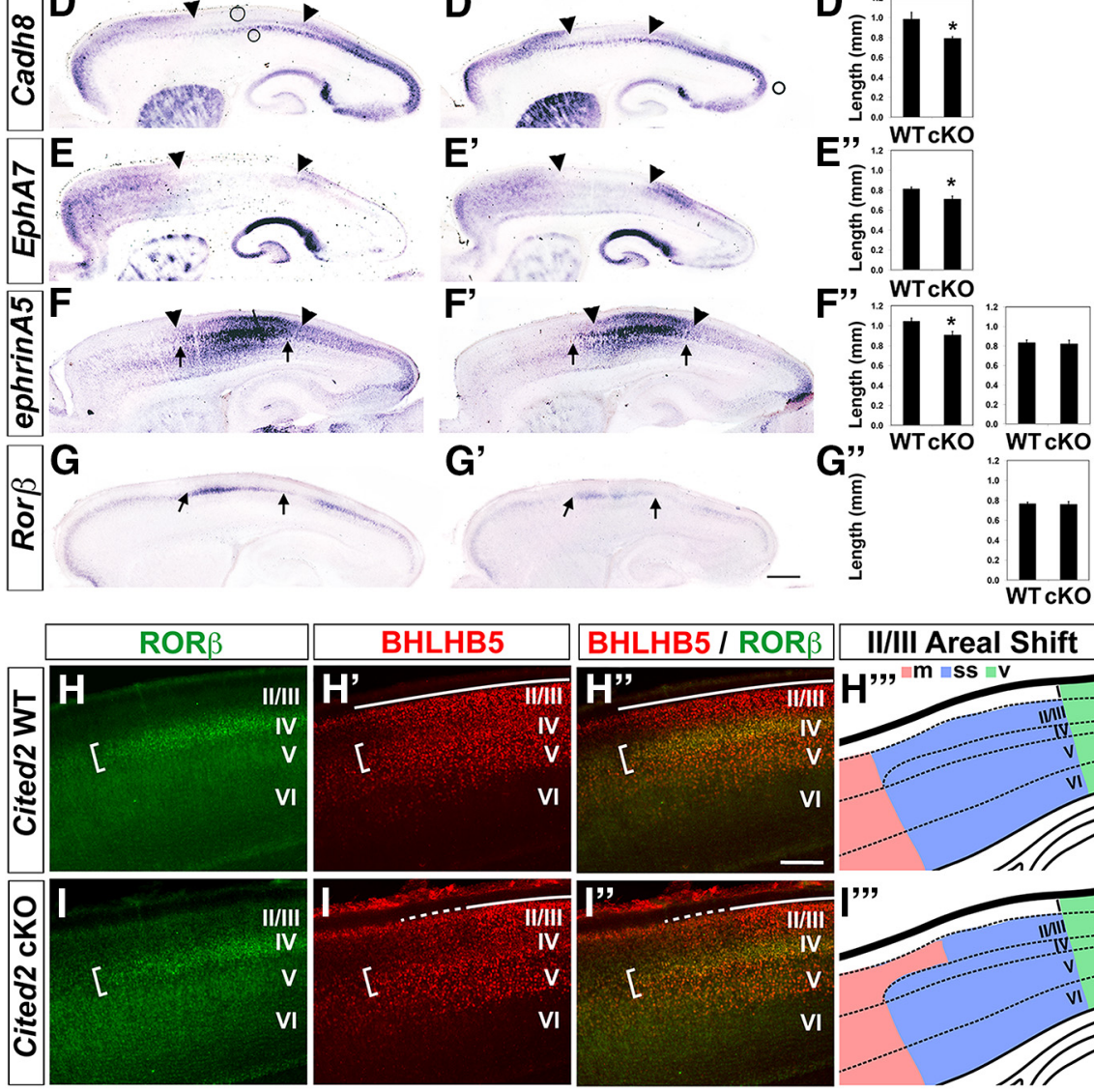

G',
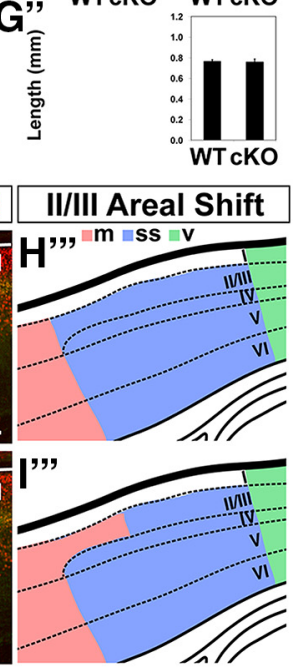

Figure 4. Neocortical surface length reduction is restricted to layers II/III of somatosensory cortex in the P3 Cited 2 cKO neocortex. A-C, Analysis of three broad neocortical areas identified by LM04 expression at P3 indicates a highly specific and substantial reduction ( 30\%) in rostrocaudal surface length of the somatosensory area (blue) in the Cited 2 cK0 neocortex, entirely accounting for the total cortical surface length reduction ( $N=8$ WT, 4 CKO). D-G, Reduced somatosensory cortex length (black arrowheads) was confirmed via expression of multiple genes either excluded from superficial layers of the somatosensory cortex (D, E; Cadh 8 , EphA7), or specifically expressed in the somatosensory cortex (F; ephrinA5). Measurements of the acallosal layer IV somatosensory cortex (black arrows), by contrast $(\boldsymbol{F}, \mathbf{G}$; ephrinA5, Ror $\beta)$, reveals that there is no significant difference in non-CPN somatosensory cortex length in Cited2 CKO mice compared with that in WT mice ( $N=8$ WT, 4 CKO). $\boldsymbol{H}^{-\boldsymbol{H}^{\prime \prime \prime}}$, In the P3 Cited2 WT neocortex, molecular markers of layer IV (green, ROR $\beta$; bracket) and the somatosensory cortex in layers II/III (red, Bhlhb5; white line) align at the motor/somatosensory border, shown in sagittal view (rostral to left). I-I'", In the P3 Cited2 cK0 neocortex, by contrast, the boundary of layer II/III expression of Bhlhb5 (white line, with additional low-level expression indicated by dashed line) is located caudal to layer IV ROR $\beta$ expression (bracket), resulting in a misalignment of molecular areal boundaries between CPN of layer II/III and acallosal layer IV ( $\boldsymbol{H}^{\prime \prime \prime}, \boldsymbol{I}^{\prime \prime \prime} ; \boldsymbol{N}=4-5$ per genotype). Scale bars: $\boldsymbol{D}-\mathbf{G}, 500 \mu \mathrm{m} ; \boldsymbol{H}-\boldsymbol{I}, 200 \mu \mathrm{m}$. Error bars denote SEM. ${ }^{*} p<0.05$; ${ }^{* *} p<0.001$ (Student's $t$ test).

To test this hypothesis, we generated cortex-specific Lmo4/ Cited 2 double cKO (dcKO) mice using Emxl-Cre recombinase. While LMO4 plays broader roles in defining neocortical areas and the barrel cortex (Kashani et al., 2006; Huang et al., 2009; Cederquist et al., 2013), we focused our analyses on motor and somatosensory superficial layer CPN. Because the Lmo4 floxed line is maintained on a mixed (C57BL/6 and S129S6) genetic background, we confirmed that Cited2 $\mathrm{cKO}$ on this background 

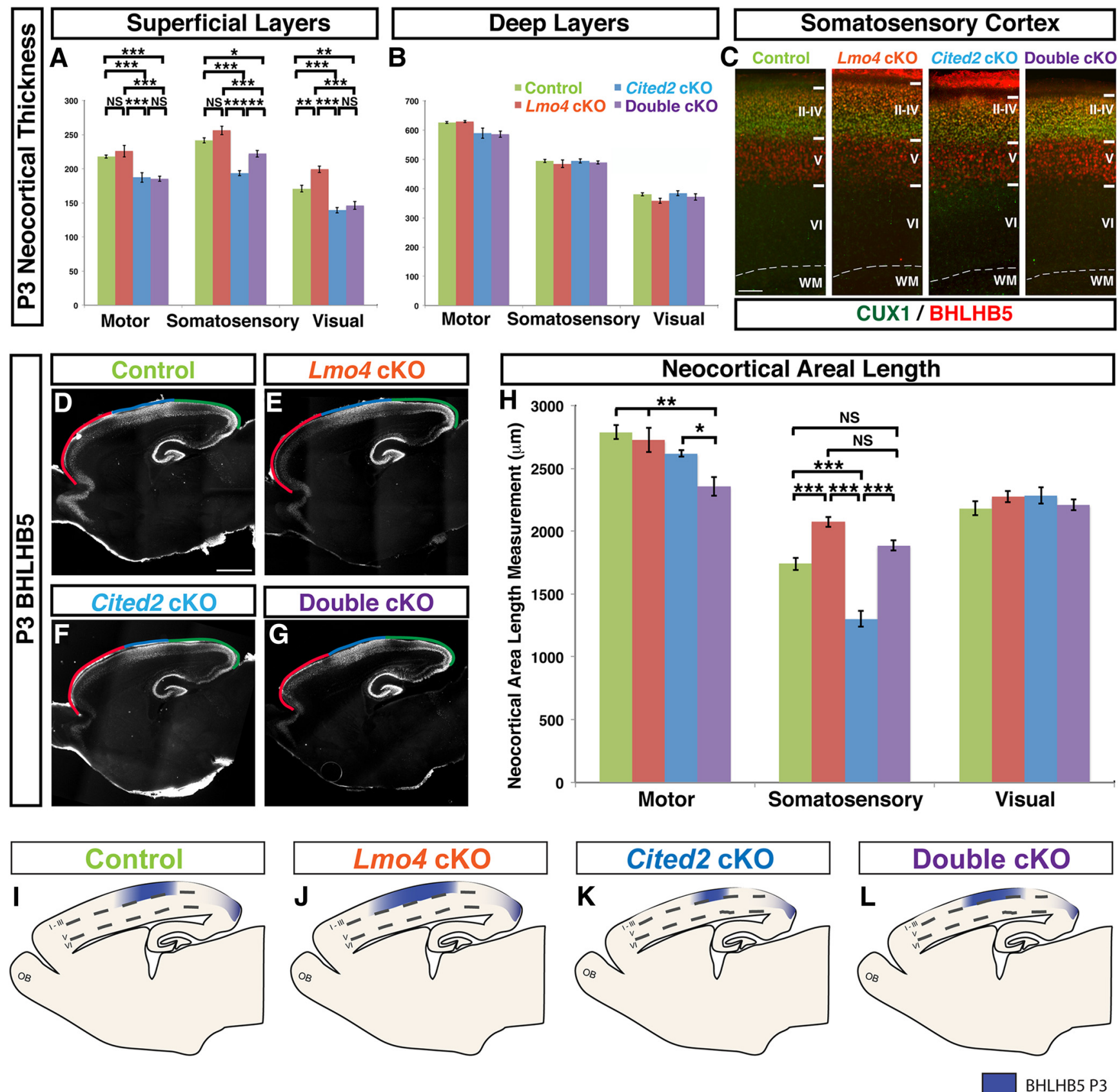

Figure 5. Additional loss of $L m 04$ function does not alter Cited $2 \mathrm{CKO}$ neocortical thickness, but does reestablish layer II/III somatosensory neocortical length at the expense of the motor cortex.

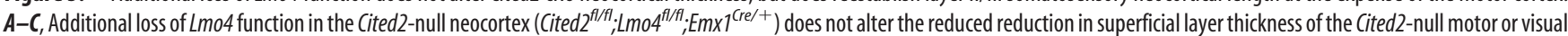
cortex, but does increase superficial layer thickness in the somatosensory cortex. Additional loss of $L m 04$ function does not alter the overall reduction in total neocortical length (data not shown). D-G, Additional loss of $L m 04$ function does, however, re-establish layer I//III somatosensory neocortical length (as measured by Bhlhb5 expression) to normal control length, at the expense of the layer II/III motor cortex. $\boldsymbol{H}$, Length of motor (rostral to Bhlhb5 layer I//III expression), somatosensory (Bhlhb5 layer I//III positive), and visual (caudal to layer II/III Bhlhb5 expression) cortical areas was

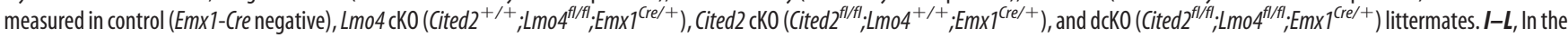
context of the shortened neocortical surface length in Cited $2 \mathrm{KO}$ mice, additional loss of $L$ mo 4 function re-establishes the length of the somatosensory area boundary, at the expense of the motor cortex length. By contrast, loss of $L m 04$ function has no effect on the overall reduced neocortical length or layer II/IIl thickness of the Cited 2 cKO neocortex. Scale bars: $\mathbf{C}, 100 \mu \mathrm{m} ; \mathbf{D}-\mathbf{G}, 1 \mathrm{~mm}$. For each neocortical area, data were analyzed by a one-way ANOVA with Tukey's post-test. For all experiments, $N=14$ controls, $7 \mathrm{Lmo} 4 \mathrm{cK} 0,7$ Cited 2 cK0, and 8 double cKO mice. Error bars denote SEM. ${ }^{*} p<$ $0.05,{ }^{* *} p<0.001,{ }^{* * *} p<0.0001$.

demonstrates the same radial and tangential reductions in neocortical size as identified on a pure C57BL/6 background. In all analyses, we compared control (Emxl-Cre negative), Lmo $4 \mathrm{cKO}$ (Cited2 $2^{+/+}$; $\left.\mathrm{Lmo4}^{\mathrm{f} / \mathrm{f} / \mathrm{f}} ; \quad \mathrm{Em} \times 1^{\mathrm{Cre} /+}\right), \quad$ Cited2 cKO $\left(\mathrm{Cited}^{\mathrm{f} / \mathrm{fl}} ; \mathrm{Lmo4}^{+/+}\right.$; $\left.\mathrm{Em} \times 1^{\mathrm{Cre} /+}\right)$, and dcKO $\left(\mathrm{Cited} 2^{\mathrm{fl} / \mathrm{fl}} ; \operatorname{Lmo} 4^{\mathrm{fl} / \mathrm{fl}} ; \mathrm{Em} \times 1^{\mathrm{Cre} /+}\right)$ littermates.

We identified that the additional loss of Lmo4 function does not alter the laminar thickness reduction of the Cited $2 \mathrm{cKO}$ mo- tor or visual cortex, but does lead to an increase in superficial layer thickness in the somatosensory cortex (Fig. 5A-C). Further, additional loss of $\mathrm{Lmo} 4$ function does not alter the overall tangential neocortical surface length (Cited2 $\mathrm{cKO}, 6204 \pm 88 \mu \mathrm{m}$; $\mathrm{dcKO}, 6453 \pm 117 \mu \mathrm{m} ; N=8$ Cited $2 \mathrm{cKO}$ and $9 \mathrm{dcKO}, p=0.09$ ), as predicted from the postmitotic restricted expression of LMO4 (Azim et al., 2009; Cederquist et al., 2013). Therefore, Lmo4 and 
Cited 2 do not genetically interact in the neocortex to control neocortical size. Additionally, misexpression of Cited 2 does not repress expression of $L m o 4$ in the motor cortex, nor induce Lmo4 expression in the somatosensory cortex (data not shown). Because Lmo4 is not expressed in neocortical progenitor regions, the maintenance of the reduced neocortical size of the Cited 2 cKO cortex in the Lmo4/Cited2 $\mathrm{dcKO}$ cortex suggests that the reduction in neocortical size in the Cited $2 \mathrm{cKO}$ neocortex results from broad Cited 2 function within the SVZ progenitors.

Strikingly, the Lmo4/Cited $2 \mathrm{dcKO}$ neocortex, while exhibiting the same reduction in overall length as the Cited2 cKO cortex, has the same somatosensory cortex size as control, exhibiting neither reduction in somatosensory length as exhibited by Cited $2 \mathrm{cKO}$ mice, nor increase in somatosensory length as seen in $\mathrm{Lmo}_{4}$ cKO mice (Kashani et al., 2006; Huang et al., 2009; Fig. 5D-L). Importantly, the shifts in areal boundaries that occur with single and double loss of Cited 2 and Lmo4 function are restricted to the motor-somatosensory boundary, with the length of the visual cortex remaining the same across all genotypes. In the context of reduced total neocortical length with loss of Cited2 function, additional loss of Lmo4 function results in a rostral shift of the motor-somatosensory boundary (to restore somatosensory cortex length), and reduction in motor cortex length. Together, these data indicate that Cited 2 and Lmo4 participate in a network of compensatory and opposing molecular controls over subtype and specific areal identity within superficial layer CPN of the somatosensory and motor cortices. Loss of Lmo4 function can rescue the superficial layer CPN arealization phenotype found in the Emx1-Cre-driven Cited2 cKO neocortex.

\section{Cited 2 is not required postmitotically for CPN areal identity} Somatosensory-specific postnatal phenotypes of Cited2-null CPN might be dependent on progenitor function of Cited2, or they could be fully independent phenotypes, indicating a biphasic function for Cited 2 during CPN development. To investigate potential postmitotic requirements for Cited 2 in acquisition of superficial layer CPN areal identity, we used NEX-promoter-driven cre-recombinase (NEX-Cre) to generate mice null for Cited 2 in early postmitotic neocortical pyramidal neurons. In this mouse line, Cre recombinase is expressed specifically in postmitotic pyramidal neurons of the neocortex and is absent from progenitors, interneurons, oligodendroglia, and astrocytes (Goebbels et al., 2006). Using a highly sensitive cre recombinase reporter (adenovirus GFP), Goebbels et al. (2006) reported that a small number of proliferating cortical cells were observed at E15.5, indicating that there is a very small window of time, if any, between cell cycle exit and onset of NEX-Cre expression. In Cited2;NEX-Cre cKO
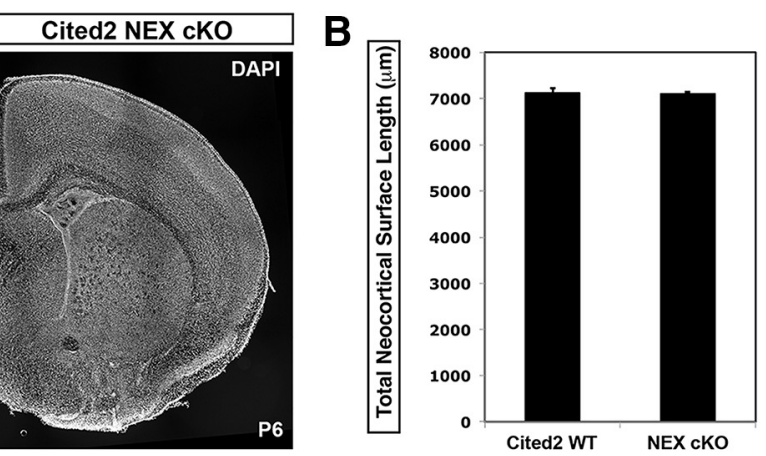

NEX-Cre Cited2 Laminar Thickness
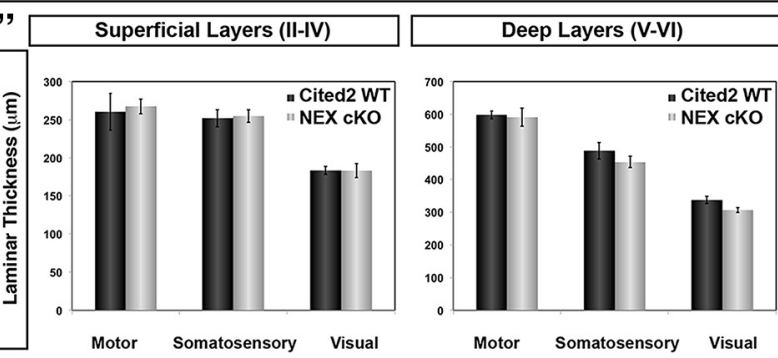

NEX-Cre Cited2 cKO Area Length
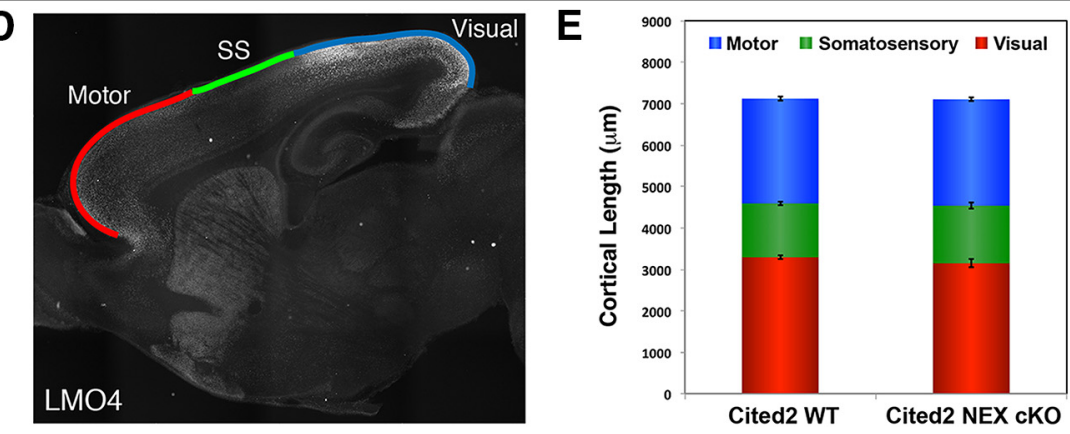

Figure 6. Excision of Cited 2 postmitotically via NEX-Cre does not alter neocortical laminar thickness or neocortical area lengths. $A, B, N E X$-Cre-mediated postmitotic excision of Cited2 does not visibly alter brain morphology or neocortical laminar development P6 (A; as indicated by DAPI nuclear staining), and there is no significant difference in P3 neocortical length between Cited2

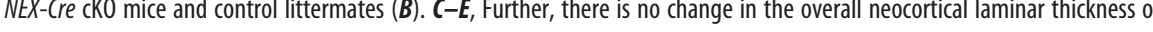
superficial or deep layers in the P3 Cited2; NEX-Cre CKO neocortex $\left(\boldsymbol{C}-\boldsymbol{C}^{\prime \prime}\right)$, nor is there a change in the length of motor, somatosensory, or visual neocortical area lengths in the Cited2; NEX-Cre cKO neocortex (D,E). For all experiments, $N=4$ WT, 4 cKO. Scale bars: A, $1 \mathrm{~mm} ; \boldsymbol{C}, 100 \mu \mathrm{m}$. Error bars denote SEM.

mice, there is highly efficient expression of a $\beta$-gal reporter across the postnatal neocortex, indicating highly efficient Cited 2 excision (data not shown).

We find that postmitotic loss of Cited 2 function in the neocortex (with NEX-Cre excision) does not overtly disrupt neocortical development or laminar organization (Fig. 6A). Further, there is no reduction in neocortical surface length or laminar thickness in Cited2;NEX-Cre cKOs (Fig. $6 B-C^{\prime \prime}$ ), indicating that the reduction in superficial layer CPN observed in the postnatal Cited2; Emx1-Cre cKO results entirely from Cited2 function in IPCs. We next investigated whether refinement of layer II/III somatosensory areal identity is disrupted following postmitotic Cited 2 loss of function, as it is following Emx1-mediated Cited2 excision. Interestingly, there is no disruption in somatosensory length in the P3 Cited2; NEX-Cre cKO neocortex (Fig. 6D,E). Together, these results indicate that the reduction in acquisition of layer II/III somatosensory areal identity results from Cited2 function in neocortical progenitors, and it is not a fully independent postmitotic function of Cited2. 
A

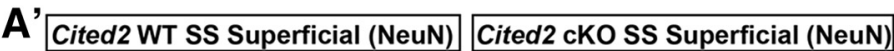
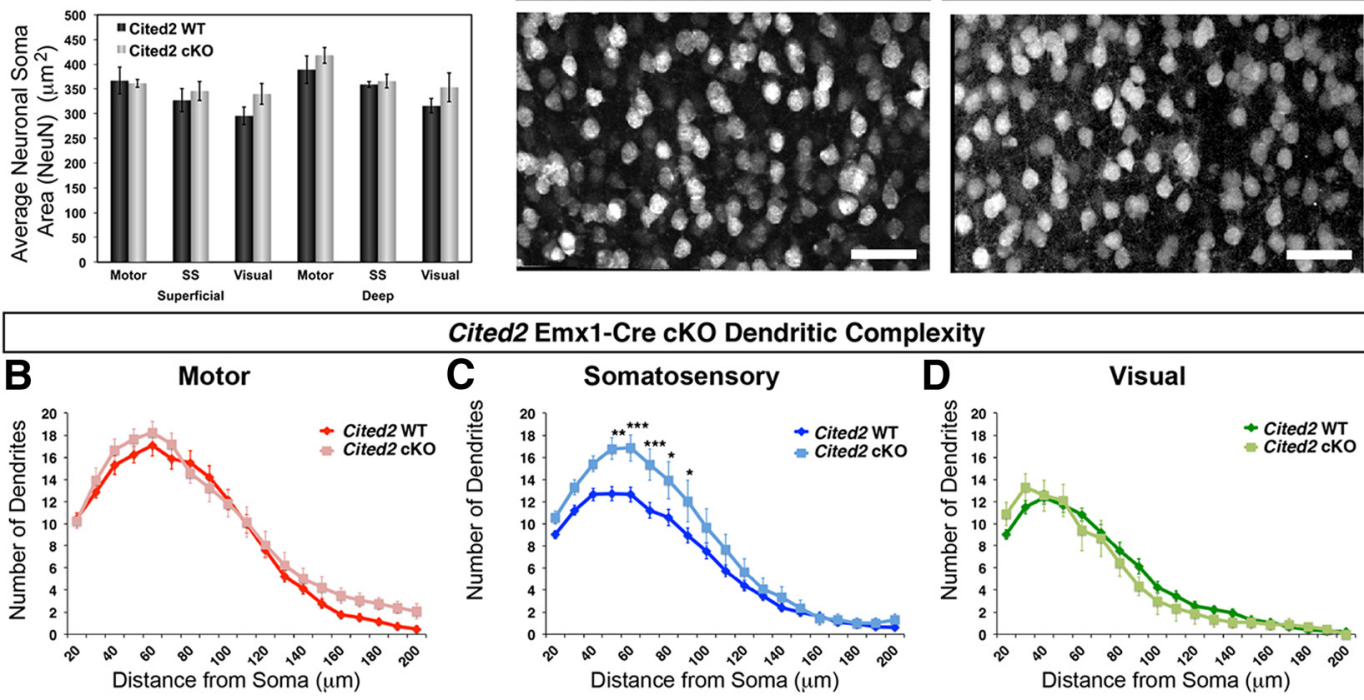

Cited2 Emx1-Cre cKO Dendritic Complexity
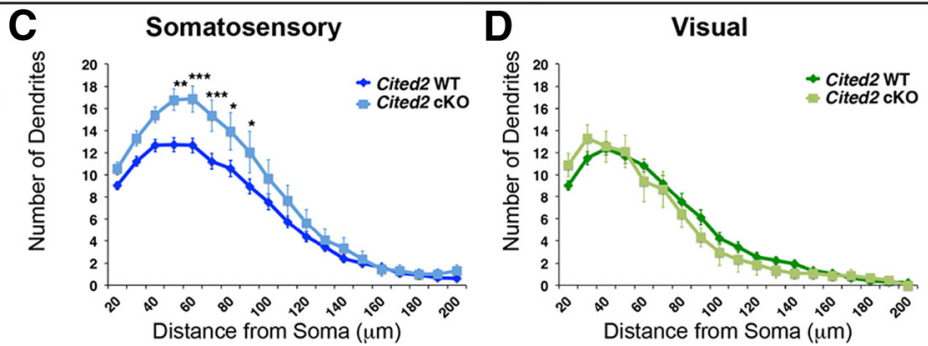

\section{B'}

WT

cKO
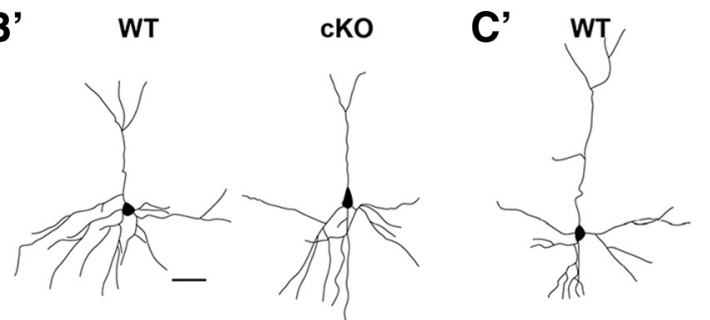

cKO

D' WT

cKO
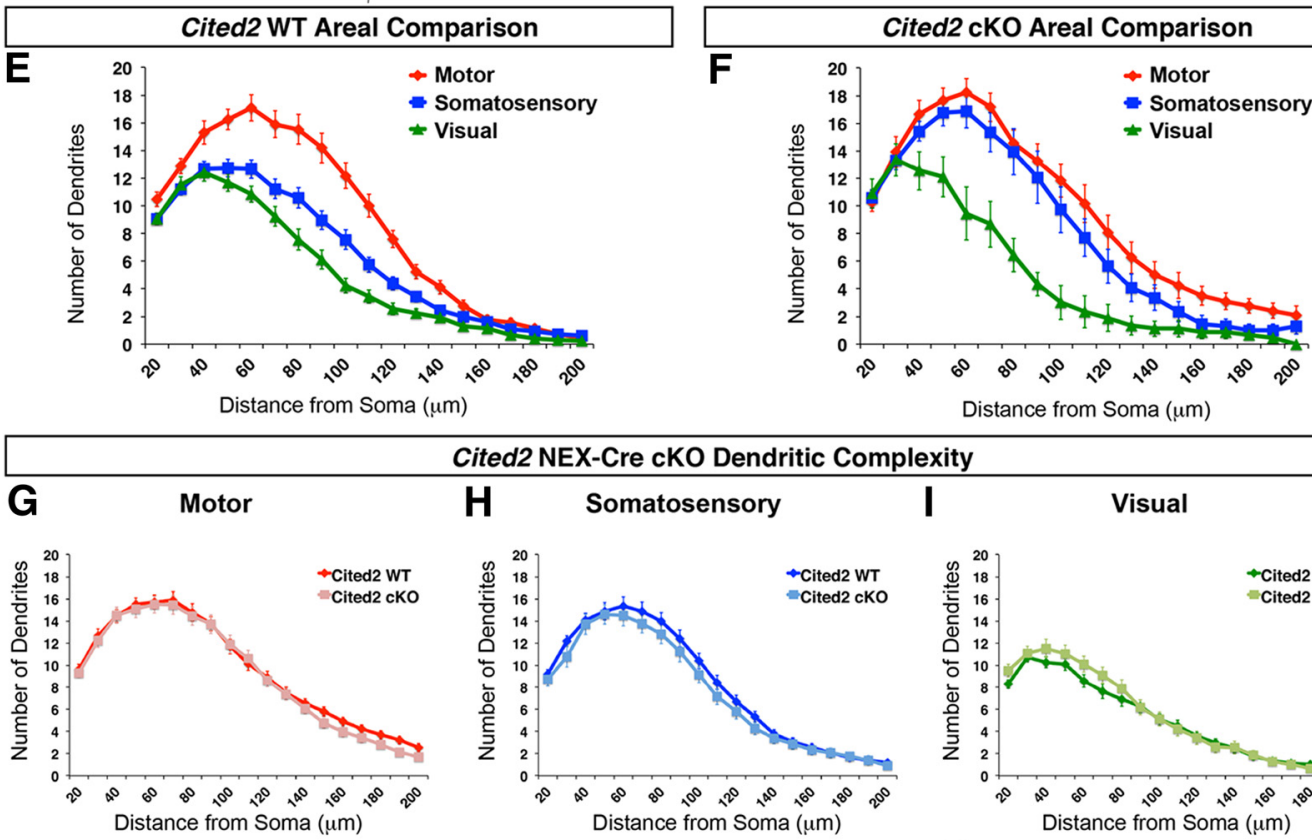

Cited2 NEX-Cre cKO Dendritic Complexity
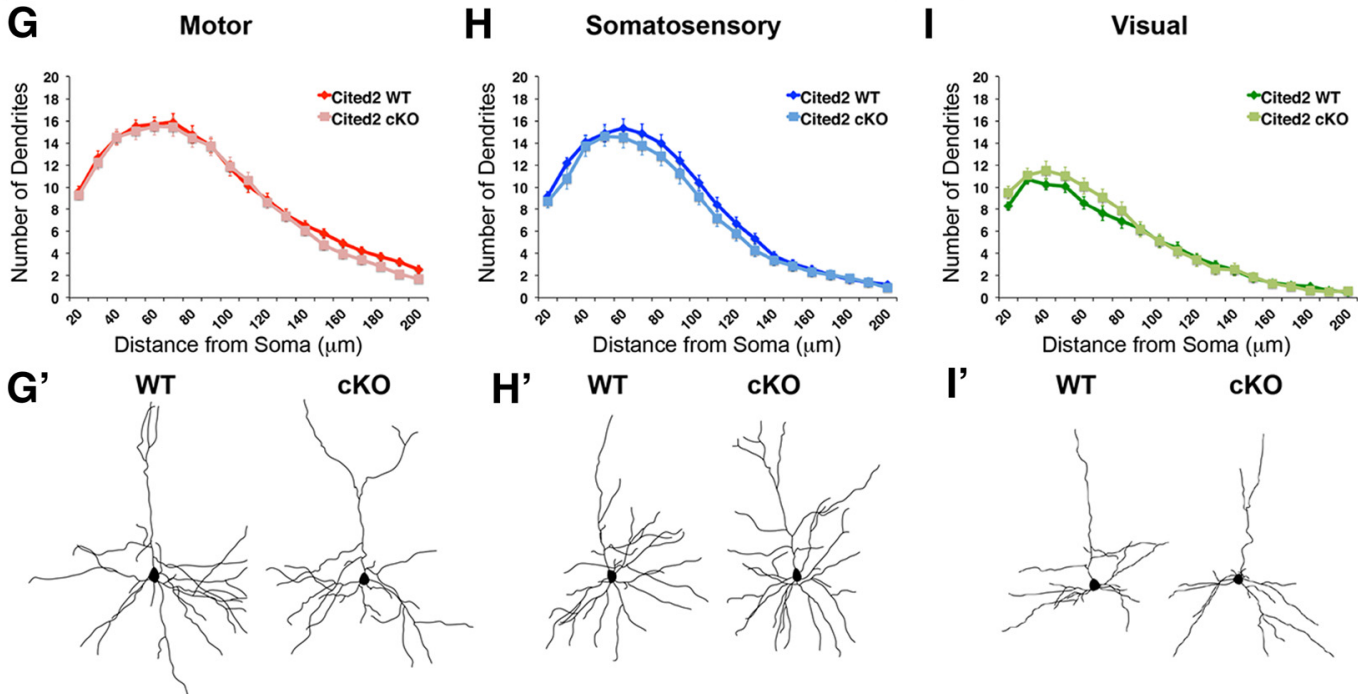

$H^{\prime}$

cKO

l'

cKO
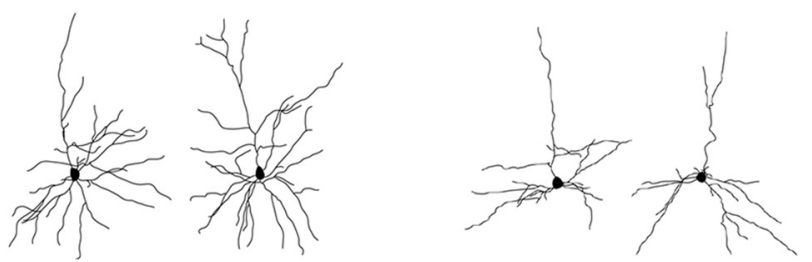

Figure 7. Loss of Cited2 function results in aberrant dendritic complexity of superficial layer somatosensory CPN. $\boldsymbol{A}, \boldsymbol{A}^{\prime}$, Neuronal soma size (NeuN area) is not affected by loss of Cited2. Increased neuronal density is evident here, consistent with the modest, but significant, increase in cell density in layer II/III of the somatosensory cortex (23\% increase, $p=0.01$ ) quantified at P6 (see Results). $N=3$ WT, 3 cKO. B-D, Dendritic complexity of layer II/III pyramidal neurons (primarily (PN) was analyzed at P22 by Golgi staining and Sholl analysis in the (Figure legend continues.) 


\section{Disruption of area-specific CPN dendritic complexity following excision of Cited 2 in progenitors}

Cited 2 functions broadly in early IPCs to both regulate generation of neocortical superficial layer CPN broadly, and to control acquisition of somatosensory molecular areal identity by layer II/III somatosensory CPN specifically. Somatosensory CPN have unique connectivity features, both in their afferent and efferent connections (Innocenti and Price, 2005; Benavides-Piccione et al., 2006). We therefore directly investigated potential functions of Cited 2 in central properties of their specific connectivity that govern the unique functionality of somatosensory CPN. We first examined neuronal soma size across all lamina and areas of Cited2; Emx-Cre cKOs to determine whether Cited2 loss of function disrupts overall size or growth of cortical projection neurons. Using NeuN to mark neuronal somata, we found no change in neuronal soma size (average soma cross-sectional area) at P21 in either deep or superficial layers (Fig. 7A). These results indicate that the reduced superficial layer thickness (Fig. 3) is not due to decreased CPN soma size.

We then investigated dendritic complexity of layer II/III CPN by Golgi staining and Sholl analysis in multiple neocortical areas (Fig. 7). While there is no significant change in layer II/III CPN dendritic complexity within the motor or visual cortex in the Cited2; Emx1-Cre cKO mice, there is a significant increase in $\mathrm{CPN}$ dendritic complexity in the somatosensory cortex (Fig. $7 B-$ $D)$. In the Cited2 WT neocortex, dendritic complexity of layer II/III CPN is distinct across different neocortical areas (Fig. 7E), with decreasing complexity rostral to caudal, as has been shown previously (Benavides-Piccione et al., 2006). Interestingly, there is a shift in total dendritic arbor distribution in Cited2; Emx1-Cre cKO somatosensory cortex CPN to more closely resemble CPN in the motor cortex, with more dendrites close to neuronal cell bodies (Fig. $7 F$ ). Together these results indicate that dendritic complexity is specifically increased in somatosensory CPN in the Cited2; Emx1-Cre cKO cortex, perhaps suggesting that Cited2null CPN might be partially "motorized" with respect to dendritic complexity.

Because dendritic arborization occurs postmitotically, we investigated whether dendritic development of somatosensory $\mathrm{CPN}$ is also perturbed following postmitotic-specific Cited 2 loss of function, or whether it is dependent on the reduction in acquisition of layer II/III somatosensory areal identity that results from Cited 2 function in neocortical progenitors. We find that NEXcre-mediated excision of Cited2 does not alter CPN soma size (data not shown) or CPN dendritic complexity in any area (Fig.

\footnotetext{
$\leftarrow$

(Figure legend continued.) Cited2;Emx1-Cre cK0 neocortex, compared with control littermates. $\boldsymbol{B}, \boldsymbol{B}^{\prime}, \boldsymbol{D}, \boldsymbol{D}^{\prime}$, There is no significant difference in dendritic complexity of layer II/III CPN in the motor cortex $\left(\boldsymbol{B}, \boldsymbol{B}^{\prime}\right)$ or visual cortex $\left(\boldsymbol{D}, \boldsymbol{D}^{\prime}\right)$ of Cited2; Emx1-Cre cK0 mice, compared with littermate controls. $\boldsymbol{C}, \boldsymbol{C}^{\prime}$, There is, however, a significant increase in dendritic complexity of layer II/III CPN in the somatosensory cortex of Cited2;Emx1-Cre cKO mice (two-way ANOVA $p<$ 0.0001). $\boldsymbol{E}$, (PN of the motor cortex are more complex than (PN of the somatosensory or visual cortex (tw0-way ANOVA $p<0.0001$ ). $\boldsymbol{F}$, In Cited2; Emx1-Cre cK0 mice, dendritic complexity of somatosensory CPN is not significantly different from the CPN of the motor cortex (two-way ANOVA $p=0.16$ ), suggesting that somatosensory (PN might be partially "motorized" in the absence of Cited2 function. G-I, Dendritic complexity of layer II/III CPN was analyzed at P22 by Golgi staining and Sholl analysis in a Cited2;NEX-Cre CKO neocortex, compared with control littermates. Following this postmitotic loss of Cited 2 function, there is no change in dendritic complexity of superficial layer pyramidal neurons in any of the primary areas examined (motor, somatosensory, or visual cortices). Scale bars, $50 \mu \mathrm{m} .{ }^{*} p<0.05,{ }^{* *} p<0.01,{ }^{* * *} p<$ 0.001, Bonferroni's post-test in $\boldsymbol{B}-\boldsymbol{F}, \boldsymbol{G} . \boldsymbol{B}-\boldsymbol{E}$ : motor, $N=17 \mathrm{WT}, 12 \mathrm{cK0}$; somatosensory, $N=$ 27 WT, 14 cK0; visual, $N=18$ WT, 9 cK0. G-I: motor, $N=38$ WT, 34 cK0; somatosensory, $N=$ 37 WT, 20 cKO; visual, $N=34$ WT, 19 cKO.
}

$7 G-I)$. Together, these data indicate that continuous postmitotic expression of Cited2 in somatosensory CPN is not required for development of areal subpopulation-appropriate CPN size and dendritic complexity; rather, alterations in CPN generation and areal identity acquisition arising from Cited 2 function in progenitors disrupts development of somatosensory-specific CPN dendritic complexity.

\section{Cited 2 is required for precise, homotopic CPN axonal connectivity}

In addition to area-specific dendritic complexity, we investigated potential Cited 2 function in CPN axonal connectivity, both broadly and in an area-specific manner. HARDI tractography based on MRI reveals that there are fewer correlated pathways passing throughout the $\mathrm{CC}$ of adult Cited $2 \mathrm{cKO}$ mouse brains compared with control (Fig. $8 A, B$ ), which is consistent with the overall reduction in superficial layer thickness and CPN number. The reduced CC is confirmed by examining myelinated fibers in midsagittal sections labeled with $\mathrm{MBP}$, revealing a significantly smaller CC area (Fig. 8C,D). Overall forebrain and midbrain area is not reduced in Cited $2 \mathrm{cKO}$ mice, as measured on these midsagittal sections (WT, 38.6 $\pm 0.7 \mu \mathrm{m}^{2}$; cKO, $37.0 \pm 0.8 \mu \mathrm{m}^{2} ; N=3$ $\mathrm{WT}, 4 \mathrm{cKO} ; p=0.18$ ), and Cited $2 \mathrm{cKO} C \mathrm{C}$ area is reduced relative to brain area $(p=0.04)$. Neocortical area, on the other hand, is reduced in Cited $2 \mathrm{cKO}$ mice (WT, $11.5 \pm 0.3 \mu \mathrm{m}^{2}$; cKO, $10.1 \pm$ $0.3 \mu \mathrm{m}^{2} ; N=3 \mathrm{WT}, 4 \mathrm{cKO} ; p=0.02$ ), suggesting that the reduced $\mathrm{CC}$ area in Cited $2 \mathrm{cKO}$ mice results from the reduced number of CPN. Of particular note, HARDI reveals an apparent additional disruption in callosal fibers in mid-CC, even though the $\mathrm{CC}$ is overall present, but reduced, by MBP staining, suggesting localized axonal disorganization in addition to fewer fibers (Fig. $8 A^{\prime}, B^{\prime}$ ).

We directly investigated precision of CPN projections at the border between motor and somatosensory cortical areas, which is especially molecularly disrupted in Cited2; Emx1 cKO mouse cortex during development. Precisely matched, focal AAV-GFP anterograde labeling demonstrates that Cited2; Emx1 cKO somatosensory $\mathrm{CPN}$ project contralateral axons imprecisely, with a bimodal distribution of axonal projections covering a more expansive target area on the contralateral hemisphere than the tightly delineated homotopic areas targeted by WT CPN (Fig. $8 E-K)$. Together, these data indicate that Cited 2 is required for precise areal-specific connectivity of somatosensory CPN, both afferent and efferent.

\section{Discussion}

CPN are a remarkably diverse set of neuronal subpopulations, requiring precise control over development of these subpopulations for proper organization and function. This study demonstrates that the transcriptional coregulator CITED2 regulates two aspects of precise CPN development in mice. Cited 2 functions broadly in embryonic progenitors of the SVZ to regulate generation of superficial layer CPN throughout the neocortex. Cited2 also functions within progenitors to establish the distinct identity and development of somatosensory CPN, in an areally restricted manner. Understanding molecular controls over development of CPN subpopulations, such as CITED2 control over somatosensory layer II/III CPN, will advance understanding of diverse system functions of $\mathrm{CPN}$, and the broad range of neurodevelopmental disorders with associated abnormalities of CPN/CC development-both overt and subtle. 

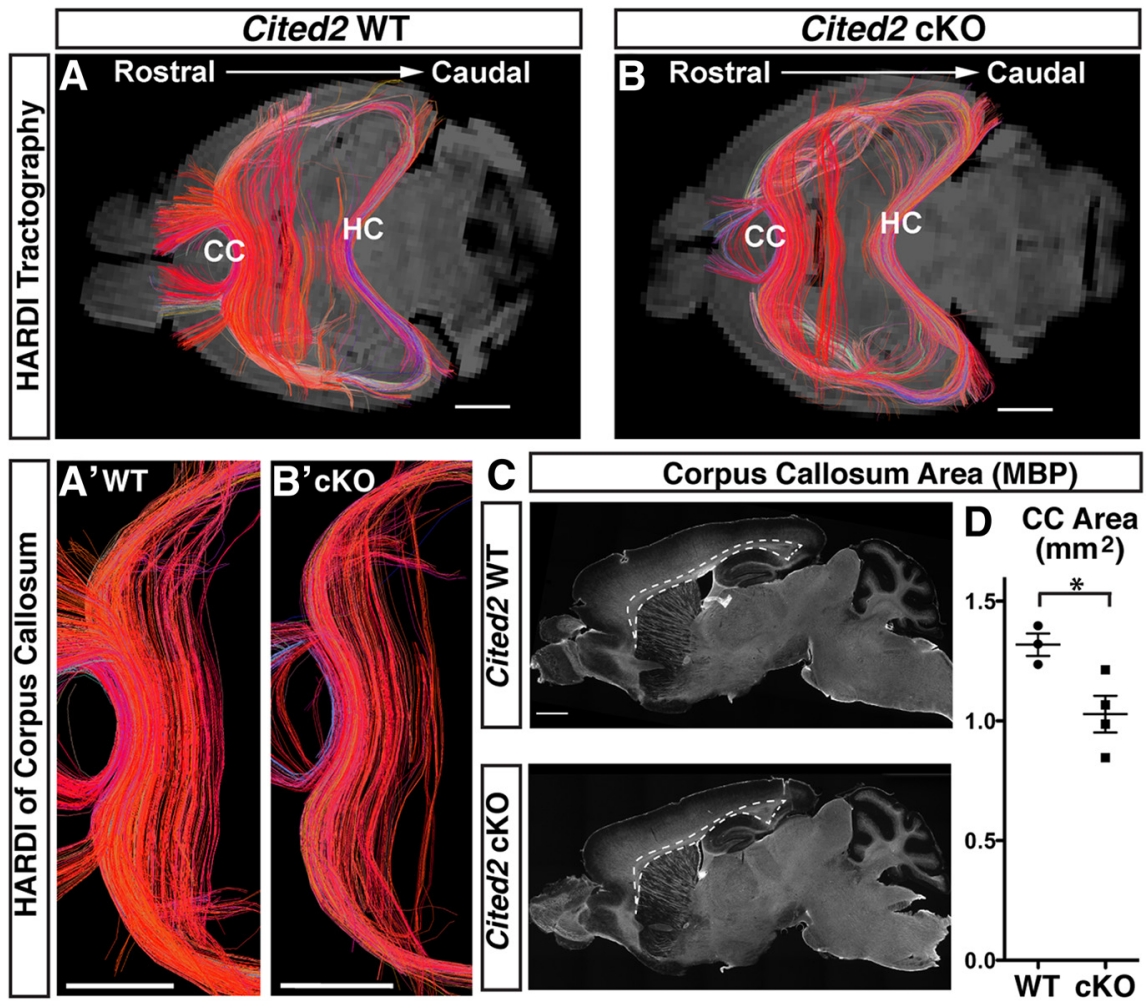

$\left(\mathrm{mm}^{2}\right)$
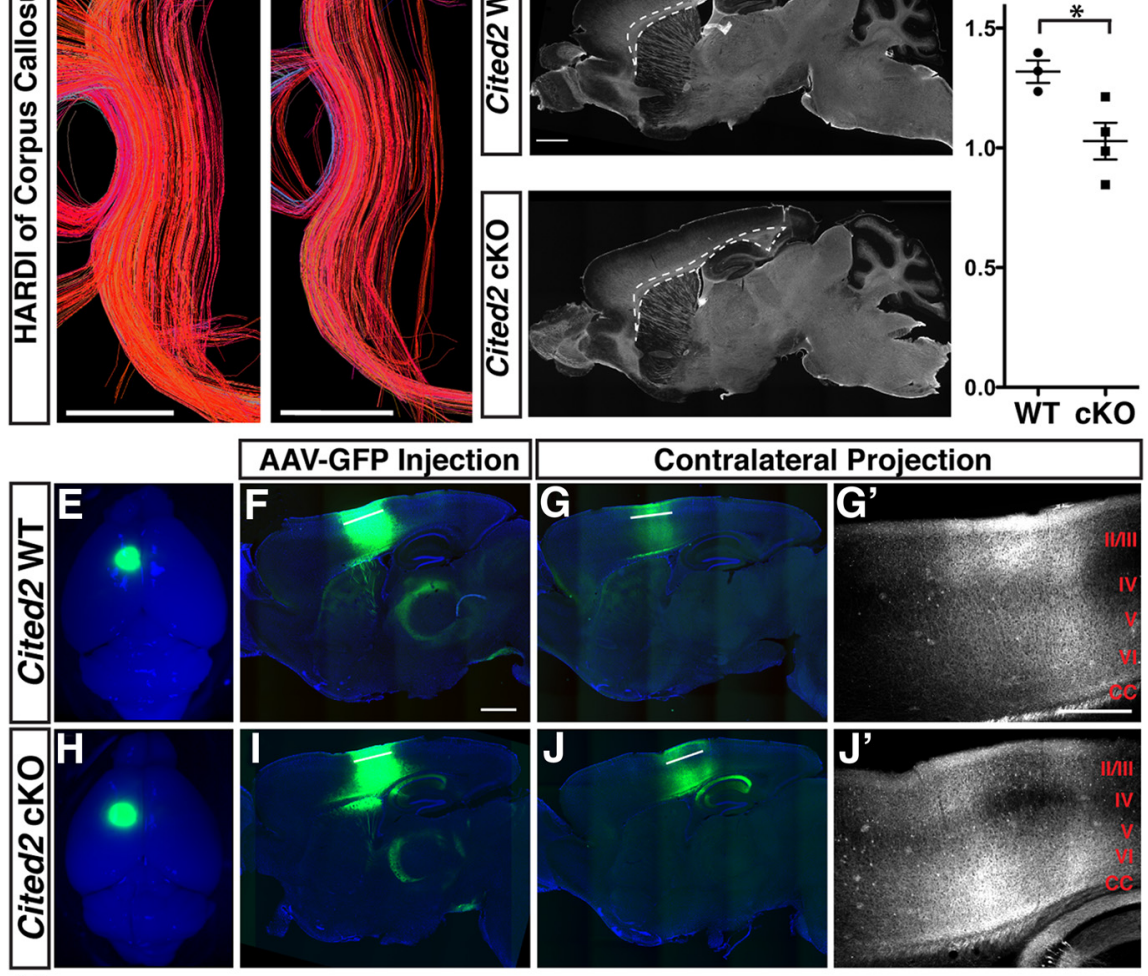

WT cKO

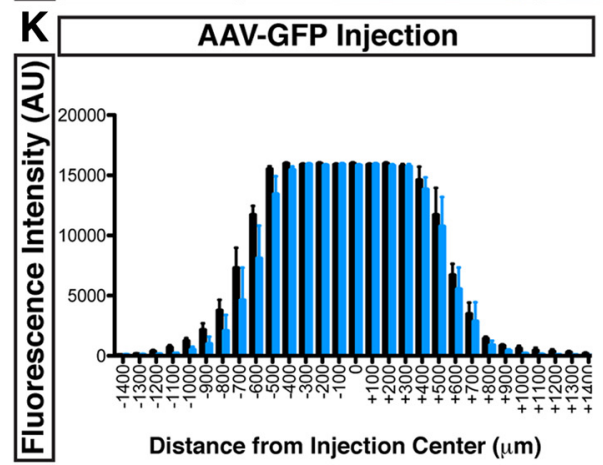

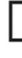

Contralateral Projection

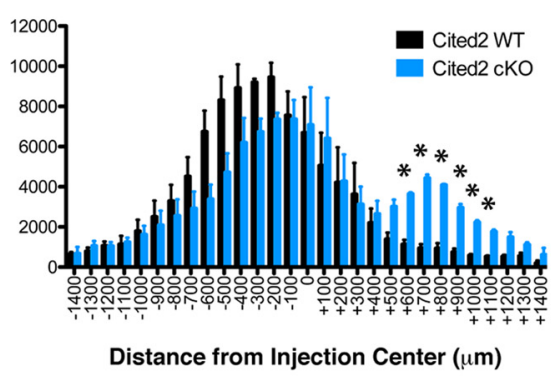

Figure 8. Interhemispheric CPN axonal connectivity is disrupted in the adult Cited2 cK0 neocortex. A, B, HARDI tractography analysis of interhemispheric connections demonstrates a significant reduction in the size of the $\mathrm{C} C$ and in the number of callosal fibers in the juvenile/young adult ( 9 weeks old) Cited2; Emx1 cre cK0 neocortex, compared with littermate controls, particularly within the mid-CC (corresponding to the somatosensory cortex). Reconstructed pathways are superimposed on the mean diffusion-weighted MRI of the brain. Pathways running between right and left are red; dorsal and ventral are green; and anterior and posterior are blue. The images do not include anterior commissure or olfactory bulb fibers; these were removed a priori to focus on the CC. Images in $\boldsymbol{A}^{\prime}$ and $\boldsymbol{B}^{\prime}$ similarly exclude hippocampal commissure fibers. $N=2$ WT, 2 CKO. C, $\boldsymbol{D}$, Staining for MBP in sagittal sections of Cited 2 WT and $\mathrm{CKO}$ brains $(\boldsymbol{C})$ followed by measurement of midsagittal $C(\mathrm{C}$ area $(\boldsymbol{D})$ identifies a reduction in $C(\mathrm{C}$ area in Cited 2 cKO brains, but demonstrates the structural integrity of the $C($ throughout all areas. $N=3$ WT, 4 CKO. E-K, To investigate precision of callosal projections in the absence of Cited 2 function, a focal injection of the anterograde tracer AAV-GFP was made in
Cited 2 regulates the precise number of TBR2+ IPCs generating layer

\section{II/III CPN}

The SVZ has expanded concomitantly with the expansion of the cerebral cortex during mammalian evolution, suggesting that an increase in IPCs contributes substantially to the evolutionary expansion of the neocortex (Kriegstein et al., 2006; Martinez-Cerdeno et al., 2006; Molnár et al., 2006; Noctor et al., 2008; Betizeau et al., 2013). Disrupting the IPC population results in reduced cortical thickness of all layers and in reduced cortical surface area (Sessa et al., 2008; Kowalczyk et al., 2009; Tuoc et al., 2013), with superficial layers most significantly affected (Pontious et al., 2008). Expression of Cited2 in the SVZ peaks during generation of superficial layers, and loss of Cited 2 function disrupts generation of superficial layers specifically. CUX2 similarly is expressed by IPCs only during late neurogenesis, and its loss perturbs superficial layer neuron production specifically (Cubelos et al., 2008), further highlighting the increased molecular regulation, in which Cited 2 has a substantial role, controlling the production of this set of neuronal populations.

The reduction in Cited2; Emx1-Cre cKO neocortical superficial layers arises from a significant reduction of TBR2 + IPCs at E15.5, the peak of superficial layer neuron birth. This reduction in TBR2 + IPCs likely results from both an increase in basal progenitor death and a decrease in IPC proliferation/cell cycle re-entry. We identified an $\sim 2$-fold increase in cell death in the Cited2 cKO neocortex, including both progenitors and postmitotic cells. Increased apoptosis is also evident in the midbrain of Cited $2^{-/}$ embryos during neural tube closure (Bamforth et al., 2001; Barbera et al., 2002), and

\footnotetext{
the somatosensory (extending into motor) neocortex at P6, and contralateral callosal projections were analyzed at 6 weeks of age. In contrast to the precise homotopic projections observed in Cited2 WTs (G), callosal projections in the Cited2 cKO somatosensory neocortex are diffuse (J). $\boldsymbol{K}$, Relative GFP fluorescence intensity was measured in matched sagittal sections of the left injected neocortical hemisphere and in the same region in the contralateral projection hemisphere, demonstrating consistent caudal spread of callosal projections in the Cited 2 cKO neocortex. $N=3$ WT, 3 cKO. ANOVA analysis finds no change in the anterior tail $(-1400$ to $-800 \mu \mathrm{m})$ or center $(-700$ to $700 \mu \mathrm{m})$ regions, but the posterior tail $(800-1400 \mu \mathrm{m})$ of the cK0 distribution is significantly different than that of the WT $(p<0.0001)$. Error bars denote SEM. ${ }^{*} p<0.05$, (Student's $t$ test) in $C$. ${ }^{*} p<0.001$ (Bonferroni post-test) in $\boldsymbol{K}$. Scale bars: $\boldsymbol{A}-\boldsymbol{B}^{\prime}, 1.5 \mathrm{~mm} ; \boldsymbol{C}, \boldsymbol{D}, \boldsymbol{F}, \boldsymbol{G}, \boldsymbol{I}, \boldsymbol{J}, 1 \mathrm{~mm}$; $G^{\prime}, J^{\prime}, 500 \mu \mathrm{m}$.
} 
CITED2 regulates death of cortical neurons in vitro after induced DNA damage (Gonzalez et al., 2008).

In addition to increased apoptosis, there is a significant reduction in the number of proliferating IPCs at E15.5, and cell-autonomous Cited 2 loss of function results in reduced cell cycle re-entry between E14.5 and E16.5, suggesting that Cited 2 function is required to maintain and expand these transit-amplifying progenitors. In line with this interpretation, Cited 2 is highly upregulated by actively proliferating transit-amplifying progenitors during induced regeneration in the olfactory epithelium (Shetty et al., 2005). Further, CITED2 controls proliferation in fibroblasts (Kranc et al., 2003), hematopoietic stem cells (Du and Yang, 2013), and nonsmall-cell lung cancer cells (Chou et al., 2012). Together, the reduction in TBR2+ IPCs in E15.5 Cited 2 cKO SVZ is likely due, at least in large part, to reduced proliferation within this progenitor population, in addition to the identified apoptosis increase.

\section{Cited 2 functions in concert with distinct transcriptional regulators}

Transcription factors that play roles in both areal and laminar identity have been identified. For example, TBR1 functions in postmitotic neurons to regulate the appropriate differentiation of layer VI broadly, as well as the establishment of frontal cortex identity (Hevner et al., 2001; Bedogni et al., 2010), and PAX6 functions in progenitor cells to both regulate neurogenesis and promote rostral identity (Bishop et al., 2002; Schuurmans et al., 2004). The dual functions of Cited 2 in CPN development appear to be quite different from these previously described mechanisms, however. Cited 2 functions broadly in SVZ progenitors to regulate the generation of (primarily) layer II/III neurons; Cited2 also has a progenitor function leading to the acquisition of appropriate areal identity of a subpopulation of superficial layer CPN. Unlike areal identity genes, such as Pax6, Bhlhb5, and Tbr1 (Joshi et al., 2008; Bedogni et al., 2010), loss of Cited2 function does not disrupt establishment of areal identity, per se. This is demonstrated by the apparently normal development of the barrel field, the hallmark of the primary somatosensory cortex, in the context of an areal disruption in somatosensory layer II/III. These results strongly suggest that CITED2 functions as part of a complex network of transcriptional coregulators that interact, compete, and compensate to regulate and refine appropriate acquisition of areal identity within a particular projection neuron subpopulation, layer II/III CPN of the somatosensory cortex.

We hypothesized that the transcriptional coregulator LMO4 might function as part of this network, regulating the acquisition of areal identity of layer II/III CPN of the motor cortex. We found that additional removal of $\mathrm{Lmo} 4$ from the Cited $2 \mathrm{cKO}$ neocortex results in a balanced reduction of molecularly defined motor and somatosensory areas within layer II/III, compared with the specific reduction in layer II/III somatosensory area with loss of Cited 2 alone, and an increase in layer II/III somatosensory area with loss of Lmo4 alone. Loss of Cited 2 and Lmo4 function, alone and in combination, does not result in complete loss of areal identity; rather, areal boundaries shift, highlighting that these transcriptional coregulators provide a mutually dependent and partially antagonistic level of precise regulation of neuronal subtype-specific areal identity acquisition.

\section{Precise connectivity of somatosensory CPN}

Laminar composition and circuit organization is distinct within the primary somatosensory neocortex compared with other neocortical areas (Polleux et al., 2001; Rash and Grove, 2006; Dehay and Kennedy, 2007; O'Leary et al., 2007). The unique misalignment of the layer II/III somatosensory neocortex relative to the layer IV barrel cortex in the Cited $2 \mathrm{cKO}$ neocortex likely profoundly perturbs this precise circuitry, as evidenced, in part, by the disrupted dendritic complexity and precise axonal connectivity of Cited $2 \mathrm{cKO} C P N$. The dendritic complexity of layer II/III CPN is specific to each neocortical area in mice, with dendritic arbors becoming progressively more complex from caudal to rostral areas (BenavidesPiccione et al., 2006). CPN of the Cited2-null somatosensory cortex display increased dendritic complexity that highly resembles that normally found in CPN of the motor cortex. This is despite the fact that CPN from the motor/somatosensory border regions, where molecular boundaries shift during development, were excluded from this analysis. Layer II/III CPN within the molecularly defined somatosensory cortex (i.e., BHLHB5+/LMO4-) of Cited2 cKO mice develop dendritic morphology of $\mathrm{CPN}$ of a normal motor cortex, indicating critical roles for Cited 2 in somatosensory CPN afferent connectivity.

Within the young adult Cited 2 cKO neocortex, CPN projections from the disrupted motor/somatosensory region are also quite imprecise, demonstrating a bimodal distribution of projections rostrocaudally within the somatosensory cortex. Further, HARDI identifies reduced callosal connectivity, particularly in the midcallosum, correlating with the somatosensory cortex. Normally, ectopic CPN projections are eliminated through activity-dependent mechanisms over the first postnatal weeks (Innocenti and Price, 2005; Luo and O'Leary, 2005; Mizuno et al., 2007; Wang et al., 2007; Zhou et al., 2013). The atypical projections identified in the adult Cited $2 \mathrm{cKO}$ neocortex might be aberrantly maintained, and might indicate earlier disrupted neuronal activity of Cited2-null CPN during somatosensory cortex development. It has recently been shown that balanced thalamic input regulates targeting of callosal projections in the somatosensory cortex (Suárez et al., 2014). Even though postmitotic loss of Cited 2 does not disrupt the metrics assessed here in somatosensory CPN, it would be of interest in future studies to assess whether Cited 2 might be induced or maintained in postmitotic somatosensory CPN in response to such balanced activity, leading to specific acquisition of other somatosensory CPN features.

In humans, even subtle disruptions in callosal connectivity are associated with defects in abstract reasoning, problem solving, and generalization (Paul et al., 2007), as well as with multiple neurodevelopmental disorders, including autism spectrum disorders (ASDs; Egaas et al., 1995; Piven et al., 1997; Herbert and Kenet, 2007; Frazier and Hardan, 2009; Hardan et al., 2009), attention deficit hyperactivity disorder (Hynd et al., 1991; Roessner et al., 2004; Seidman et al., 2005), Tourette's syndrome (Plessen et al., 2006), and schizophrenia (Swayze et al., 1990; Tibbo et al., 1998; Innocenti et al., 2003; Wolf et al., 2008). Further, perturbed dendritic complexity of layer II/III CPN is observed in multiple neurodevelopmental disorders, including Rett syndrome (Armstrong et al., 1995; Kishi and Macklis, 2004), ASD (Mukaetova-Ladinska et al., 2004; Srivastava et al., 2012), and schizophrenia (Broadbelt et al., 2002). Greater understanding of molecular regulation of precise temporal and area-specific development of diverse CPN subpopulations might elucidate perturbations underlying such complex neurodevelopmental disorders.

\section{Conclusions}

Together, our results demonstrate that Cited2 functions differently from previously described mechanisms to regulate two 
stages of precise CPN development, acting in neocortical progenitors to both broadly regulate generation of superficial layer CPN throughout the neocortex, and in an areally restricted manner to refine the distinct identity and precise connectivity of somatosensory CPN. This novel biology of Cited 2 adds yet another layer of complexity to the multistage control and regulation of neocortical development.

\section{References}

Armstrong D, Dunn JK, Antalffy B, Trivedi R (1995) Selective dendritic alterations in the cortex of Rett syndrome. J Neuropathol Exp Neurol 54:195-201. CrossRef Medline

Azim E, Shnider SJ, Cederquist GY, Sohur US, Macklis JD (2009) Lmo4 and Clim 1 progressively delineate cortical projection neuron subtypes during development. Cereb Cortex 19 [Suppl 1]:i62-i69. CrossRef Medline

Bamforth SD, Bragança J, Eloranta JJ, Murdoch JN, Marques FI, Kranc KR, Farza H, Henderson DJ, Hurst HC, Bhattacharya S (2001) Cardiac malformations, adrenal agenesis, neural crest defects and exencephaly in mice lacking Cited2, a new Tfap2 co-activator. Nat Genet 29:469-474. CrossRef Medline

Bamforth SD, Bragança J, Farthing CR, Schneider JE, Broadbent C, Michell AC, Clarke K, Neubauer S, Norris D, Brown NA, Anderson RH, Bhattacharya S (2004) Cited2 controls left-right patterning and heart development through a Nodal-Pitx2c pathway. Nat Genet 36:1189-1196. CrossRef Medline

Barbera JP, Rodriguez TA, Greene ND, Weninger WJ, Simeone A, Copp AJ, Beddington RS, Dunwoodie S (2002) Folic acid prevents exencephaly in Cited2 deficient mice: Creation of CITED2 null mice. Hum Mol Genet 11:283-293. CrossRef Medline

Bedogni F, Hodge RD, Elsen GE, Nelson BR, Daza RA, Beyer RP, Bammler TK, Rubenstein JL, Hevner RF (2010) Tbrl regulates regional and laminar identity of postmitotic neurons in developing neocortex. Proc Natl Acad Sci U S A 107:13129-13134. CrossRef Medline

Benavides-Piccione R, Hamzei-Sichani F, Ballesteros-Yáñez I, DeFelipe J, Yuste R (2006) Dendritic size of pyramidal neurons differs among mouse cortical regions. Cereb Cortex 16:990-1001. Medline

Betizeau M, Cortay V, Patti D, Pfister S, Gautier E, Bellemin-Ménard A, Afanassieff M, Huissoud C, Douglas RJ, Kennedy H, Dehay C (2013) Precursor diversity and complexity of lineage relationships in the outer subventricular zone of the primate. Neuron 80:442-457. CrossRef Medline

Bhattacharya S, Michels CL, Leung MK, Arany ZP, Kung AL, Livingston DM (1999) Functional role of $\mathrm{p} 35$ srj, a novel p300/CBP binding protein, during transactivation by HIF-1. Genes Dev 13:64-75. CrossRef Medline

Bishop KM, Rubenstein JL, O'Leary DD (2002) Distinct actions of Emxl, Emx2, and Pax6 in regulating the specification of areas in the developing neocortex. J Neurosci 22:7627-7638. Medline

Broadbelt K, Byne W, Jones LB (2002) Evidence for a decrease in basilar dendrites of pyramidal cells in schizophrenic medial prefrontal cortex. Schizophr Res 58:75-81. CrossRef Medline

Catapano LA, Arnold MW, Perez FA, Macklis JD (2001) Specific neurotrophic factors support the survival of cortical projection neurons at distinct stages of development. J Neurosci 21:8863-8872. Medline

Cederquist GY, Azim E, Shnider SJ, Padmanabhan H, Macklis JD (2013) Lmo4 establishes rostral motor cortex projection neuron subtype diversity. J Neurosci 33:6321-6332. CrossRef Medline

Chen Y, Doughman YQ, Gu S, Jarrell A, Aota S, Cvekl A, Watanabe M, Dunwoodie SL, Johnson RS, van Heyningen V, Kleinjan DA, Beebe DC, Yang YC (2008) Cited2 is required for the proper formation of the hyaloid vasculature and for lens morphogenesis. Development 135:29392948. CrossRef Medline

Chen Y, Carlson EC, Chen ZY, Hamik A, Jain MK, Dunwoodie SL, Yang YC (2009) Conditional deletion of Cited 2 results in defective corneal epithelial morphogenesis and maintenance. Dev Biol 334:243-252. CrossRef Medline

Chou YT, Hsieh CH, Chiou SH, Hsu CF, Kao YR, Lee CC, Chung CH, Wang YH, Hsu HS, Pang ST, Shieh YS, Wu CW (2012) CITED2 functions as a molecular switch of cytokine-induced proliferation and quiescence. Cell Death Differ 19:2015-2028. CrossRef Medline

Cubelos B, Sebastián-Serrano A, Kim S, Moreno-Ortiz C, Redondo JM, Walsh CA, Nieto M (2008) Cux-2 controls the proliferation of neuronal intermediate precursors of the cortical subventricular zone. Cereb Cortex 18:1758-1770. CrossRef Medline
Dehay C, Kennedy H (2007) Cell-cycle control and cortical development. Nat Rev Neurosci 8:438-450. CrossRef Medline

Deng M, Pan L, Xie X, Gan L (2010) Requirement for Lmo4 in the vestibular morphogenesis of mouse inner ear. Dev Biol 338:38-49. CrossRef Medline

Du J, Yang YC (2013) Cited2 in hematopoietic stem cell function. Curr Opin Hematol 20:301-307. CrossRef Medline

Dye CA, El Shawa H, Huffman KJ (2011) A lifespan analysis of intraneocortical connections and gene expression in the mouse I. Cereb Cortex 21: 1311-1330. CrossRef Medline

Egaas B, Courchesne E, Saitoh O (1995) Reduced size of corpus callosum in autism. Arch Neurol 52:794-801. CrossRef Medline

Fame RM, MacDonald JL, Macklis JD (2011) Development, specification, and diversity of callosal projection neurons. Trends Neurosci 34:41-50. CrossRef Medline

Frazier TW, Hardan AY (2009) A meta-analysis of the corpus callosum in autism. Biol Psychiatry 66:935-941. CrossRef Medline

Freedman SJ, Sun ZY, Kung AL, France DS, Wagner G, Eck MJ (2003) Structural basis for negative regulation of hypoxia-inducible factor1alpha by CITED2. Nat Struct Biol 10:504-512. CrossRef Medline

Glenn DJ, Maurer RA (1999) MRG1 binds to the LIM domain of Lhx2 and may function as a coactivator to stimulate glycoprotein hormone alphasubunit gene expression. J Biol Chem 274:36159-36167. CrossRef Medline

Goebbels S, Bormuth I, Bode U, Hermanson O, Schwab MH, Nave KA (2006) Genetic targeting of principal neurons in neocortex and hippocampus of NEX-Cre mice. Genesis 44:611-621. CrossRef Medline

Gonzalez YR, Zhang Y, Behzadpoor D, Cregan S, Bamforth S, Slack RS, Park DS (2008) CITED2 signals through peroxisome proliferator-activated receptor- $\gamma$ to regulate death of cortical neurons after DNA damage. J Neurosci 28:5559-5569. CrossRef Medline

Greig LC, Woodworth MB, Galazo MJ, Padmanabhan H, Macklis JD (2013) Molecular logic of neocortical projection neuron specification, development and diversity. Nat Rev Neurosci 14:755-769. CrossRef Medline

Grove EA, Fukuchi-Shimogori T (2003) Generating the cerebral cortical area map. Annu Rev Neurosci 26:355-380. CrossRef Medline

Guo H, Hong S, Jin XL, Chen RS, Avasthi PP, Tu YT, Ivanco TL, Li Y (2000) Specificity and efficiency of Cre-mediated recombination in Emx1-Cre knock-in mice. Biochem Biophys Res Commun 273:661-665. CrossRef Medline

Hardan AY, Pabalan M, Gupta N, Bansal R, Melhem NM, Fedorov S, Keshavan MS, Minshew NJ (2009) Corpus callosum volume in children with autism. Psychiatry Res 174:57-61. CrossRef Medline

Haubensak W, Attardo A, Denk W, Huttner WB (2004) Neurons arise in the basal neuroepithelium of the early mammalian telencephalon: a major site of neurogenesis. Proc Natl Acad Sci U S A 101:3196-3201. CrossRef Medline

Hayashi S, Tenzen T, McMahon AP (2003) Maternal inheritance of Cre activity in a Sox2Cre deleter strain. Genesis 37:51-53. CrossRef Medline

Herbert MR, Kenet T (2007) Brain abnormalities in language disorders and in autism. Pediatr Clin North Am 54:563-583, vii. Medline

Hevner RF, Shi L, Justice N, Hsueh Y, Sheng M, Smiga S, Bulfone A, Goffinet AM, Campagnoni AT, Rubenstein JL (2001) Tbrl regulates differentiation of the preplate and layer 6. Neuron 29:353-366. CrossRef Medline

Huang Z, Kawase-Koga Y, Zhang S, Visvader J, Toth M, Walsh CA, Sun T (2009) Transcription factor Lmo4 defines the shape of functional areas in developing cortices and regulates sensorimotor control. Dev Biol 327: 132-142. CrossRef Medline

Hynd GW, Semrud-Clikeman M, Lorys AR, Novey ES, Eliopulos D, Lyytinen H (1991) Corpus callosum morphology in attention deficit-hyperactivity disorder: morphometric analysis of MRI. J Learn Disabil 24: 141-146. CrossRef Medline

Innocenti GM, Price DJ (2005) Exuberance in the development of cortical networks. Nat Rev Neurosci 6:955-965. CrossRef Medline

Innocenti GM, Ansermet F, Parnas J (2003) Schizophrenia, neurodevelopment and corpus callosum. Mol Psychiatry 8:261-274. CrossRef Medline

Jin XL, Guo H, Mao C, Atkins N, Wang H, Avasthi PP, Tu YT, Li Y (2000) Emx1-specific expression of foreign genes using "knock-in" approach. Biochem Biophys Res Commun 270:978-982. CrossRef Medline

Joshi PS, Molyneaux BJ, Feng L, Xie X, Macklis JD, Gan L (2008) Bhlhb5 
regulates the postmitotic acquisition of area identities in layers II-V of the developing neocortex. Neuron 60:258-272. CrossRef Medline

Kashani AH, Qiu Z, Jurata L, Lee SK, Pfaff S, Goebbels S, Nave KA, Ghosh A (2006) Calcium activation of the LMO4 transcription complex and its role in the patterning of thalamocortical connections. J Neurosci 26: 8398-8408. CrossRef Medline

Kishi N, Macklis JD (2004) MECP2 is progressively expressed in postmigratory neurons and is involved in neuronal maturation rather than cell fate decisions. Mol Cell Neurosci 27:306-321. CrossRef Medline

Kowalczyk T, Pontious A, Englund C, Daza RA, Bedogni F, Hodge R, Attardo A, Bell C, Huttner WB, Hevner RF (2009) Intermediate neuronal progenitors (basal progenitors) produce pyramidal-projection neurons for all layers of cerebral cortex. Cereb Cortex 19:2439-2450. CrossRef Medline

Kranc KR, Bamforth SD, Bragança J, Norbury C, van Lohuizen M, Bhattacharya $S$ (2003) Transcriptional coactivator Cited2 induces Bmil and Mel18 and controls fibroblast proliferation via Ink4a/ARF. Mol Cell Biol 23:7658-7666. CrossRef Medline

Kranc KR, Schepers H, Rodrigues NP, Bamforth S, Villadsen E, Ferry H, Bouriez-Jones T, Sigvardsson M, Bhattacharya S, Jacobsen SE, Enver T (2009) Cited2 is an essential regulator of adult hematopoietic stem cells. Stem Cell 5:659-665. CrossRef Medline

Kriegstein A, Noctor S, Martínez-Cerdeño V (2006) Patterns of neural stem and progenitor cell division may underlie evolutionary cortical expansion. Nat Rev Neurosci 7:883-890. CrossRef Medline

Lee S, Lee B, Joshi K, Pfaff SL, Lee JW, Lee SK (2008) A regulatory network to segregate the identity of neuronal subtypes. Dev Cell 14:877-889. CrossRef Medline

Lomber SG, Payne BR, Rosenquist AC (1994) The spatial relationship between the cerebral cortex and fiber trajectory through the corpus callosum of the cat. Behav Brain Res 64:25-35. CrossRef Medline

Lou X, Sun S, Chen W, Zhou Y, Huang Y, Liu X, Shan Y, Wang C (2011) Negative feedback regulation of NF-kappaB action by CITED2 in the nucleus. J Immunol 186:539-548. CrossRef Medline

Luo L, O'Leary DD (2005) Axon retraction and degeneration in development and disease. Annu Rev Neurosci 28:127-156. CrossRef Medline

Macdonald JL, Verster A, Berndt A, Roskams AJ (2010) MBD2 and MeCP2 regulate distinct transitions in the stage-specific differentiation of olfactory receptor neurons. Mol Cell Neurosci 44:55-67. CrossRef Medline

Maguire CA, Bovenberg MS, Crommentuijn MH, Niers JM, Kerami M, Teng J, Sena-Esteves M, Badr CE, Tannous BA (2013) Triple bioluminescence imaging for in vivo monitoring of cellular processes. Mol Ther Nucleic Acids 2:e99. CrossRef Medline

Martinez-Cerdeno V, Noctor SC, Kriegstein AR (2006) The role of intermediate progenitor cells in the evolutionary expansion of the cerebral cortex. Cereb Cortex 16 [Suppl 1]:i152-i161. Medline

Michell AC, Bragança J, Broadbent C, Joyce B, Franklyn A, Schneider JE, Bhattacharya S, Bamforth SD (2010) A novel role for transcription factor Lmo4 in thymus development through genetic interaction with Cited2. Dev Dyn 239:1988-1994. CrossRef Medline

Mitchell BD, Macklis JD (2005) Large-scale maintenance of dual projections by callosal and frontal cortical projection neurons in adult mice. J Comp Neurol 482:17-32. CrossRef Medline

Miyata T, Kawaguchi A, Saito K, Kawano M, Muto T, Ogawa M (2004) Asymmetric production of surface-dividing and nonsurface-dividing cortical progenitor cells. Development 131:3133-3145. CrossRef Medline

Mizuno H, Hirano T, Tagawa Y (2007) Evidence for activity-dependent cortical wiring: formation of interhemispheric connections in neonatal mouse visual cortex requires projection neuron activity. J Neurosci 27: 6760-6770. CrossRef Medline

Molnár Z, MétinC, Stoykova A, Tarabykin V, Price DJ, Francis F, Meyer G, Dehay C, Kennedy H (2006) Comparative aspects of cerebral cortical development. Eur J Neurosci 23:921-934. CrossRef Medline

Molyneaux BJ, Arlotta P, Fame RM, MacDonald JL, MacQuarrie KL, Macklis JD (2009) Novel subtype-specific genes identify distinct subpopulations of callosal projection neurons. J Neurosci 29:12343-12354. CrossRef Medline

Mori T, Wanaka A, Taguchi A, Matsumoto K, Tohyama M (1995) Differential expressions of the eph family of receptor tyrosine kinase genes (sek, elk, eck) in the developing nervous system of the mouse. Mol Brain Res 29:325-335.

Motulsky HJ, Brown RE (2006) Detecting outliers when fitting data with nonlinear regression - a new method based on robust nonlinear regression and the false discovery rate. BMC Bioinformatics 7:123. CrossRef Medline

Mukaetova-Ladinska EB, Arnold H, Jaros E, Perry R, Perry E (2004) Depletion of MAP2 expression and laminar cytoarchitectonic changes in dorsolateral prefrontal cortex in adult autistic individuals. Neuropathol Appl Neurobiol 30:615-623. CrossRef Medline

Noctor SC, Martínez-CerdeñoV, Ivic L, Kriegstein AR (2004) Cortical neurons arise in symmetric and asymmetric division zones and migrate through specific phases. Nat Neurosci 7:136-144. CrossRef Medline

Noctor SC, Martínez-Cerdeño V, Kriegstein AR (2008) Distinct behaviors of neural stem and progenitor cells underlie cortical neurogenesis. J Comp Neurol 508:28-44. CrossRef Medline

O'Leary DD, Chou SJ, Sahara S (2007) Area patterning of the mammalian cortex. Neuron 56:252-269. CrossRef Medline

Olivares R, Montiel J, Aboitiz F (2001) Species differences and similarities in the fine structure of the mammalian corpus callosum. Brain Behav Evol 57:98-105. CrossRef Medline

Paul LK, Brown WS, Adolphs R, Tyszka JM, Richards LJ, Mukherjee P, Sherr EH (2007) Agenesis of the corpus callosum: genetic, developmental and functional aspects of connectivity. Nat Rev Neurosci 8:287-299. CrossRef Medline

Pinto L, Drechsel D, Schmid MT, Ninkovic J, Irmler M, Brill MS, Restani L, Gianfranceschi L, Cerri C, Weber SN, Tarabykin V, Baer K, Guillemot F, Beckers J, Zecevic N, Dehay C, Caleo M, Schorle H, Götz M (2009) AP2 $\gamma$ regulates basal progenitor fate in a region- and layer-specific manner in the developing cortex. Nat Neurosci 12:1229-1237. CrossRef Medline

Piven J, Bailey J, Ranson BJ, Arndt S (1997) An MRI study of the corpus callosum in autism. Am J Psychiatry 154:1051-1056. CrossRef Medline

Plessen KJ, Grüner R, Lundervold A, Hirsch JG, Xu D, Bansal R, Hammar A, Lundervold AJ, Wentzel-Larsen T, Lie SA, Gass A, Peterson BS, Hugdahl K (2006) Reduced white matter connectivity in the corpus callosum of children with Tourette syndrome. J Child Psychol Psychiatry 47:1013-1022. CrossRef Medline

Polleux F, Dehay C, Goffinet A, Kennedy H (2001) Pre- and post-mitotic events contribute to the progressive acquisition of area-specific connectional fate in the neocortex. Cereb Cortex 11:1027-1039. CrossRef Medline

Pontious A, Kowalczyk T, Englund C, Hevner RF (2008) Role of intermediate progenitor cells in cerebral cortex development. Dev Neurosci 30: 24-32. CrossRef Medline

Preis JI, Wise N, Solloway MJ, Harvey RP, Sparrow DB, Dunwoodie SL (2006) Generation of conditional Cited2 null alleles. Genesis 44: 579-583. CrossRef Medline

Rash BG, Grove EA (2006) Area and layer patterning in the developing cerebral cortex. Curr Opin Neurobiol 16:25-34. CrossRef Medline

Roessner V, Banaschewski T, Uebel H, Becker A, Rothenberger A (2004) Neuronal network models of ADHD-lateralization with respect to interhemispheric connectivity reconsidered. Eur Child Adolesc Psychiatry 13 [Suppl 1]:171-179. Medline

Rosen GD, Azoulay NG, Griffin EG, Newbury A, Koganti L, Fujisaki N, Takahashi E, Grant PE, Truong DT, Fitch RH, Lu L, Williams RW (2013) Bilateral subcortical heterotopia with partial callosal agenesis in a mouse mutant. Cereb Cortex 23:859-872. CrossRef Medline

Schuurmans C, Armant O, Nieto M, Stenman JM, Britz O, Klenin N, Brown C, Langevin LM, Seibt J, Tang H, Cunningham JM, Dyck R, Walsh C, Campbell K, Polleux F, Guillemot F (2004) Sequential phases of cortical specification involve Neurogenin-dependent and -independent pathways. EMBO J 23:2892-2902. CrossRef Medline

Seidman LJ, Valera EM, Makris N (2005) Structural brain imaging of attention-deficit/hyperactivity disorder. Biol Psychiatry 57:12631272. CrossRef Medline

Sessa A, Mao CA, Hadjantonakis AK, Klein WH, Broccoli V (2008) Tbr2 directs conversion of radial glia into basal precursors and guides neuronal amplification by indirect neurogenesis in the developing neocortex. Neuron 60:56-69. CrossRef Medline

Shetty RS, Bose SC, Nickell MD, McIntyre JC, Hardin DH, Harris AM, McClintock TS (2005) Transcriptional changes during neuronal death and 
replacement in the olfactory epithelium. Mol Cell Neurosci 30:583-600. Medline

Sholl DA (1953) Dendritic organization in the neurons of the visual and motor cortices of the cat. J Anat 87:387-406. Medline

Song JW, Mitchell PD, Kolasinski J, Ellen Grant P, Galaburda AM, Takahashi E (2015) Asymmetry of white matter pathways in developing human brains. Cereb Cortex 25:2883-2893. CrossRef Medline

Srivastava DP, Woolfrey KM, Jones KA, Anderson CT, Smith KR, Russell TA, Lee H, Yasvoina MV, Wokosin DL, Ozdinler PH, Shepherd GM, Penzes P (2012) An autism-associated variant of Epac2 reveals a role for Ras/ Epac2 signaling in controlling basal dendrite maintenance in mice. PLoS Biol 10:e1001350. CrossRef Medline

Suárez R, Fenlon LR, Marek R, Avitan L, Sah P, Goodhill GJ, Richards LJ (2014) Balanced interhemispheric cortical activity is required for correct targeting of the corpus callosum. Neuron 82:1289-1298. CrossRef Medline

Swayze VW 2nd, Andreasen NC, Ehrhardt JC, Yuh WT, Alliger RJ, Cohen GA (1990) Developmental abnormalities of the corpus callosum in schizophrenia. Arch Neurol 47:805-808. CrossRef Medline

Takahashi E, Dai G, Wang R, Ohki K, Rosen GD, Galaburda AM, Grant PE, Wedeen VJ (2010) Development of cerebral fiber pathways in cats revealed by diffusion spectrum imaging. Neuroimage 49:1231-1240. CrossRef Medline

Tibbo P, Nopoulos P, Arndt S, Andreasen NC (1998) Corpus callosum shape and size in male patients with schizophrenia. Biol Psychiatry 44: 405-412. CrossRef Medline

Tuch DS, Reese TG, Wiegell MR, Wedeen VJ (2003) Diffusion MRI of complex neural architecture. Neuron 40:885-895. CrossRef Medline
Tuoc TC, Narayanan R, Stoykova A (2013) BAF chromatin remodeling complex: cortical size regulation and beyond. Cell Cycle 12:2953-2959. CrossRef Medline

Wang CL, Zhang L, Zhou Y, Zhou J, Yang XJ, Duan SM, Xiong ZQ, Ding YQ (2007) Activity-dependent development of callosal projections in the somatosensory cortex. J Neurosci 27:11334-11342. CrossRef Medline

Weninger WJ, Lopes Floro K, Bennett MB, Withington SL, Preis JI, Barbera JP, Mohun TJ, Dunwoodie SL (2005) Cited2 is required both for heart morphogenesis and establishment of the left-right axis in mouse development. Development 132:1337-1348. CrossRef Medline

Wilson CJ (1987) Morphology and synaptic connections of crossed corticostriatal neurons in the rat. J Comp Neurol 263:567-580. CrossRef Medline

Withington SL, Scott AN, Saunders DN, Lopes Floro K, Preis JI, Michalicek J, Maclean K, Sparrow DB, Barbera JP, Dunwoodie SL (2006) Loss of Cited2 affects trophoblast formation and vascularization of the mouse placenta. Dev Biol 294:67-82. CrossRef Medline

Wolf RC, Höse A, Frasch K, Walter H, Vasic N (2008) Volumetric abnormalities associated with cognitive deficits in patients with schizophrenia. Eur Psychiatry 23:541-548. CrossRef Medline

Xu B, Qu X, Gu S, Doughman YQ, Watanabe M, Dunwoodie SL, Yang YC (2008) Cited2 is required for fetal lung maturation. Dev Biol 317:95-105. CrossRef Medline

Zhou J, Wen Y, She L, Sui YN, Liu L, Richards LJ, Poo MM (2013) Axon position within the corpus callosum determines contralateral cortical projection. Proc Natl Acad Sci U S A 110:E2714-E2723. CrossRef Medline 